\title{
LA FLOTA DE LA SOCIEDAD BALLENERA DE MAGALLANES: HISTORIAS Y OPERACIONES EN LOS MARES AUSTRALES (1905-1916)
}

DANIEL QUIROZ

\section{RESUMEN}

La Sociedad Ballenera de Magallanes, una de las principales compañías balleneras chilenas, se forma como sociedad anónima en 1906 y se disuelve apenas diez años más tarde. Durante este corto lapso de tiempo la empresa utilizará en sus operaciones un total de nueve buques, cinco buques-cazadores a vapor, dos buques-factoría, también a vapor, y dos buques utilizados como pontones, es decir, como depósitos de carbón y de aceite. La Sociedad Ballenera de Magallanes usará dos sistemas para el procesamiento de las carcasas de las ballenas, uno representado por su planta terrestre de bahía Águila y el otro por su buque factoría Gobernador Bories. La caza de las ballenas era realizada por los "catchers", los "almirantes" de la flota ballenera. En este trabajo nos interesa mostrar los orígenes de la flota, las características técnicas más significativas de sus buques, los trabajos que desarrollaron para la Sociedad Ballenera de Magallanes entre los años 1905 y 1916 y las historias particulares de cada buque después de su venta.

PALABRAS CLAVE: caza de ballenas, flota ballenera, Sociedad Ballenera de Magallanes, Punta Arenas.

\section{THE WHALING FLEET OF SOCIEDAD BALLENERA DE MAGALLANES: HISTORIES AND OPERATIONS IN THE SOUTHERN SEAS (1905-1916)}

\section{ABSTRACT}

Sociedad Ballenera de Magallanes, a leading Chilean whaling company, formed as a limited company in 1906 and dissolved ten years later. During this period the company will use in whaling nine ships, five catchers, two factory ships, and two pontoon ships, i.e. deposits of coal and oil. Sociedad Ballenera de Magallanes used two systems for the processing of carcasses of whales, the first represented by the bahía Águila land station and the second by factory ship Gobernador Bories. Whaling was carried 
out by the "catchers", the "admirals" of the whaling fleet. In this paper we want to show the origins of the fleet, the most significant technical features of ships, the operations developed for the Sociedad Ballenera de Magallanes between 1905 and 1916, and the individual histories of each ship after the sale.

KEY WORDS: whaling, whaling fleet, Sociedad Ballenera de Magallanes, Punta Arenas.

\section{ANTECEDENTES}

La Sociedad Ballenera de Magallanes, una de las principales compañías balleneras chilenas, se forma como sociedad anónima en 1906 y se disuelve, diez años más tarde, en 1916. Se han escrito un conjunto importante de trabajos que han abordado de modo global el funcionamiento de la sociedad y explorado su importancia no solo durante esa década sino también en sus proyecciones (Navarro 1907; Martinic 1972, 1973, 1975, 1977, 1987, 2004; Braun 1985; Filippi 1997; Nicholls 2010; Duque 2010). En este trabajo queremos estudiar el proceso de formación de la flota de la Sociedad Ballenera de Magallanes, enfatizando las características técnicas de cada uno de los buques y las funciones que desarrollaron para el cumplimiento de los objetivos de la empresa. Nos interesa también revisar la historia de cada uno de los buques luego de ser traspasados a sus nuevos dueños producto de la disolución de la sociedad y el desmantelamiento de su flota.

La Sociedad Ballenera de Magallanes nace a partir de una compañía previa, bastante exitosa: la sociedad en comandita De Bruyne, Andresen y Cia, formada a fines de 1904 por los empresarios magallánicos Mauricio Braun, Alejandro Menéndez Behety, Pedro A. de Bruyne y Adolfo Andresen (Martinic 1977: 314; cf. Navarro 1907: 208b). Los estatutos de la sociedad en comandita se registran recién el 15 de septiembre de 1905, indicando que estará formada por los señores Pedro A. de Bruyne y Adolfo Andresen como gestores y seis socios comanditarios, su capital social será de once mil libras esterlinas y su objetivo la pesca de ballenas, focas y otros cetáceos, el refinamiento de aceite, otros derivados de estas industrias y demás negocios que convengan a la Sociedad ${ }^{1}$. Da-

1 Registro Notarial de Sociedades $N^{\circ} 25,1905$, Notario de Magallanes, volumen 85, fs. 58v-59. Archivo Nacional [Santiago de Chile]. dos los buenos resultados de la compañía, sus socios deciden formar en 1906 la Sociedad Ballenera de Magallanes, registrando sus escrituras en Punta Arenas el 30 de marzo de $1906^{2}$ y constituyéndose legalmente, con sus estatutos aprobados, en abril de ese mismo año ${ }^{3}$. Los objetivos de la sociedad eran la pesca de ballenas, focas, lobos marinos $i$ las demás operaciones accesorias a esta industria, con un capital social de $£ 100.000^{4}$. A pesar de sus grandes expectativas, los socios no lograron reunir el capital social proyectado, de modo que solicitan, a mediados de 1909, su disminución a £60.000, solicitud que fue denegada por el Gobierno, expresando en su conclusión que dicha denegación es sin perjuicio del derecho de los accionistas para liquidar la sociedad i formar una nueva con menor capital 5 . Frente a esta "recomendación" los accionistas solicitan la disolución de la sociedad, la que es autorizada ${ }^{6}, y$ deciden formar una nueva, con el mismo nombre y objetivos de la sociedad anterior, pero con un capital menor, $£ 60.000$, empresa que queda constituida legalmente y con sus estatutos aprobados a comienzos de $1911^{7}$. Luego de algunos años exitosos, una serie de problemas, tanto internos como externos (sobre todo relacionados con el inicio de la primera guerra mundial), harán imposible finalmente seguir operando en buenas condiciones y la Sociedad Ballenera de Magallanes solicitará nuevamente autorización para disolverse

2 Registro Notarial de Sociedades $\mathrm{N}^{\circ} 15,1906$, Notario de Magallanes, volumen 93, fs. 40-50. Archivo Nacional [Santiago de Chile].

3 D.S. N ${ }^{\circ}$ 2,905 [Ministerio de Hacienda], 7 de julio de 1906, Diario Oficial (Santiago de Chile), 27 de julio de 1906.

4 Estatutos de la Sociedad Ballenera de Magallanes. Diario Oficial (Santiago de Chile), 27 de julio de 1906.

5 D.S. $\mathrm{N}^{\circ}$ 1,468 [Ministerio de Hacienda], 17 de Agosto de 1909, Diario Oficial (Santiago de Chile), 30 de agosto de 1910

6 D.S. № 1980 [Ministerio de Hacienda], 19 de Agosto de 1910. Diario Oficial (Santiago de Chile), 30 de agosto de 1910.

7 D.S. № 70 [Ministerio de Hacienda], 14 de enero de 1911, Diario Oficial (Santiago de Chile), 20 de enero de 1911. 
y liquidarse, esta vez en forma definitiva, la que recibirá a mediados de julio de $1916^{8}$.

La Sociedad Ballenera de Magallanes usó en sus diversas actividades un conjunto de nueve embarcaciones, cinco buques-cazadores, a vapor (Almirante Montt, Almirante Valenzuela, Almirante Uribe, Almirante Señoret y Almirante Goñi), tres buques-factoría, también a vapor (Gobernador Bories (I), Gobernador Bories (II) y Rubens) y un velero (Cornelia Jacoba) usado como pontón, es decir como depósitos de carbón y de aceite (Navarro 1907, Martinic 1972, Braun 1985). La sociedad fue dueña por poco tiempo de otros buques, del vapor Telefon, rescatado de un naufragio, ocurrido a fines de 1908 en aguas antárticas (Heyburn \& Stenersen 1989) y del velero Wilhelmine, adquirido en 1911 como buque de apoyo para las operaciones de la sociedad en Chiloé.

\section{MATERIALES}

Las fuentes que hemos usado para desarrollar este trabajo podemos agruparlas en las siguientes categorías: [a] las Memorias del Ministerio de Marina ${ }^{9}$ y otros Fondos Ministeriales y Notariales conservados en el Archivo Nacional de Chile, que tienen datos sobre la Sociedad Ballenera de Magallanes y sus buques; [b] los periódicos regionales, tales como Chile Austral, El Comercio y La Unión de Punta Arenas y La Cruz del Sur de Ancud, que muestran noticias sobre actividades específicas de la sociedad y también de sus buques; [c] el Diario Oficial donde aparecen los decretos sobre la formación, estatutos, modificaciones y disolución de la sociedad y los permisos de navegación de sus buques; [d] los libros de registro de los buques mercantes del mundo, principalmente Det Norske Veritas [Noruega], Lloyd's Register of British \& Foreign Shipping [Reino Unido], American Lloyd's Register of American and Foreign Shipping [Estados Unidos] y Record of American \& Foreign Shipping [Estados Unidos] pero también la Lista Oficial de la Marina Mercante Nacional [Chile], que entregan información técnica e histórica sobre

8 D.S. $N^{\circ} 1074$ [Ministerio de Hacienda], 8 de julio de 1916, Diario Oficial (Santiago de Chile), 13 de julio de 1916.

9 Revisamos también las Memorias del Ministerio de Marina impresas, publicadas anualmente, para el período 1905-1915. cada uno de los buques de la flota ballenera magallánica; y, finalmente, [e] datos inéditos proporcionados por diversos investigadores extranjeros especializados en el tema naviero y, particularmente en asuntos balleneros.

También pudimos consultar un pequeño conjunto de fotografías de los buques, en distintos momentos y circunstancias. Sin embargo, las imágenes más valiosas son, sin duda, aquellas que forman parte de una colección de 36 fotografías que donara al Instituto de la Patagonia de la Universidad de Magallanes don Bernardo de Bruyne, hijo de Pedro de Bruyne, antiguo Director y Gerente de la Sociedad Ballenera de Magallanes (Martinic 1972: 41). La mayoría de estas fotografías fueron tomadas por E. B. Binnie $e^{10}$ entre 1907 y 1908. Entre esas imágenes hay varias fotografías de los buques, operando tanto en bahía Águila como en isla Decepción, algunas de las que hemos usado para ilustrar este trabajo.

Todos estos materiales son analizados dentro de un contexto informativo constituido por una revisión exhaustiva de lo que se ha publicado sobre el tema hasta la fecha, considerando sus coincidencias y contradicciones.

\section{LA FORMACIÓN DE LA FLOTA}

La Sociedad de Bruyne, Andresen y Co. y el primer buque ballenero, el Almirante Montt

La caza moderna de ballenas se caracterizaba principalmente por usar un arpón explosivo lanzado desde un cañón montado en la proa de un buque ballenero a vapor (Brown 1976: 25). Los buques cazadores eran pequeñas embarca-

10 Edward B. Binnie nace en 1884 en Port Stanley, Islas Malvinas. Como funcionario del gobierno insular asume en 1907 el cargo de Oficial de Aduanas, uno de los responsables de supervisar y regular la emergente industria ballenera antártica. En esta calidad se embarca en el Gobernador Bories en su campaña antártica de 1907-1908. Binnie escribe un interesante diario de la expedición y toma un conjunto muy notable de fotografías. Copias de algunas de estas fotografías son conservadas por el Archivo Iconógrafico del Instituto de la Patagonia. En 1912 fue Magistrado en la Tierra de Graham y las Shetlands del Sur, el primero en tierras antárticas, y entre 1914 y 1927 Magistrado en las Georgias del Sur. Se traslada a Noruega donde trabajó intermitentemente en la industria ballenera. Muere en Sandefjord, Noruega, en 1956 (Hart 2009; cf. Hart 2006). 
ciones que parecen remolcadores, de 100 a 300 toneladas, de construcción fuerte, propulsadas a vapor y cuya tripulación era de unos once hombres (Hohman 1935: 632 Estos buques eran "puro motor", donde todo era sacrificado por la fuerza y la velocidad, de modo que podía cazar las ballenas a siete nudos y luego remolcarlas a la base en la costa (Jackson 1978: 159). El buque ideal debía ser rápido, poderoso, maniobrable y virtualmente imposible de hundirse (Davis et al 1997: $500)^{11}$. Estos buques costaban cerca de $£ 5,000$, sin considerar el equipamiento (cañón, líneas, arpones) para la caza (Tonnesen y Johnsen 1982: 39). En una planta costera las carcasas de los cetáceos eran procesadas para extraerles las barbas, el aceite y un abono proveniente de la carne y los huesos (Tonnesen y Johnsen 1882: 39-40). Este modelo de explotación de los cetáceos, desarrollado gracias a las innovaciones introducidas en el norte de Noruega por Svend Foyn, dominó la industria ballenera durante el último cuarto del siglo XIX y las primeras décadas del siglo XX (Tønnessen y Johnsen 1982: 16-36).

La sociedad De Bruyne, Andresen y Cia. debe ser considerada, sin duda, como la primera compañía con un sistema "moderno" de caza de ballenas del país ${ }^{12}$. La sociedad implementará este sistema $^{13}$ en aguas magallánicas durante el año 1905, construyendo una planta terrestre para el procesamiento de las ballenas en bahía Águila y adquiriendo un vapor ballenero nuevo en Noruega. En 1906 la Sociedad Ballenera y Pescadora de Valdivia iniciará sus actividades en la planta de San Carlos de Corral, y en 1909 la A/S Pacific lo hará en su planta en la Isla de San Pedro, cerca de Que-

11 Según las convenciones internacionales el término "whale catcher" (o ballenero) se refiere a "un buque utilizado para la caza, captura, muerte, seguimiento y remolque de las ballenas Convenio internacional para la regulación de la pesca de la ballena, artículo $n^{\circ} 2$ [Washington, 1946].

12 Las empresas balleneras chilenas más antiguas, como la Mathieu \& Brañas [1861] y su sucesora la Toro \& Martínez [1895], de Talcahuano, o la Compañía Chilena de Balleneros [1871], de Valparaíso (Aguayo-Lobo et al 1998), no utilizaban los métodos de cacería que constituyen por definición la forma "moderna" de cazar ballenas (Tønnesen y Johnsen 1982: 7).

13 El sistema había sido probado por A.A. Andresen, instalando un cañón arponero en el Magallanes, vapor de la Braun \& Blanchard, con el que había cazado en 1903 las tres primeras ballenas en aguas del Pacífico (Martinic 1973). llón (Chiloé). Con estas instalaciones Chile ingresa en la primera década del siglo XX en el universo de la caza moderna de ballenas.

La sociedad encarga a los astilleros Framnæs mekaniske Væerksted ${ }^{14}$, en Sandefjord, Noruega, la construcción del primer ballenero ${ }^{15}$ a vapor que operaría bajo bandera chilena y comisionará a uno de los socios gestores, el capitán Adolfo Andresen, para que viaje en 1905 a Noruega a recibirlo. El Almirante Montt, será entregado al capitán Andresen, en Sandefjord, durante el mes de julio de 1905, inaugurando así la serie de cinco "almirantes" que la flota de la Sociedad Ballenera de Magallanes tendrá en mares magallánicos y antárticos entre 1906 y 1916.

El Almirante Montt, número $56^{16}$ de la lista del astillero Framnaes, era un buque con casco de acero, de 91,9 pies de eslora, 18,0 pies de manga y 10,9 pies de puntal, con un tonelaje de 123 GRT y 23 NRT $^{17}$. Estaba propulsado por una hélice movida por un motor a vapor compuesto de triple expansión ${ }^{18}$, de tres cilindros, con una potencia de

14 Framnæes Mekaniske Værksted, astillero conocido como Framnæes, se encuentra situado en el sector sur oriental del fiordo de Sandefjord, en el sur de Noruega. Una serie de pequeños talleres de construcción naval fueron reunidos por Chr. Christensen en 1898 para formar una empresa dedicada a la construcción de buques, muchos de ellos dedicados a la cacería de ballenas (Bogen 1948). Funcionó hasta 1986.

15 Estos buques se denominaban en inglés "whale catcher" o simplemente "catcher" y en noruego "hvalbåt". En español se usa indistintamente los términos "cazador ballenero" o "ballenero".

16 Los astilleros usan este número para identificar un buque particular que está construyendo y normalmente es parte de un sistema correlativo cronológico de numeración. En español se llama "número de construcción", en inglés "yard number", y en noruego "bygget number".

17 GRT [Gross Register Tonnage] representa el volumen interno total de una embarcación. Una tonelada bruta de registro es igual a un volumen de 100 pies cúbicos $(\sim 2.83$ $\mathrm{m}^{3}$ ). El tonelaje bruto de registro no es una medida del peso o desplazamiento del buque. NRT [Net Register Tonnage] representa el volumen disponible que el buque tiene para llevar carga y/o pasajeros.

18 El motor compuesto permite que "el vapor entre a un cilindro a alta presión y, después de haber movido el piston en este cilindro, salga a uno o más cilindros mayores donde los pistones se mueven por expansión directa" (Riegel 1921: 107). En el motor compuesto de triple expansión el vapor debe pasar por tres cilindros, de tamaño creciente. En el Almirante Montt el primer cilindro (de alta presión) tenía un diámetro de 11", mientras que el segundo era de 18 " y el tercero de 29". 
52 NHP y 296 IHP $^{19}$, alimentado por una caldera a carbón de 9,3×9,3 pies con dos hornos de 36 pulgadas de diámetro, que generaba vapor a 180 $\mathrm{PSI}^{20}$. El motor y la caldera habían sido construidos por Akers mekaniske Verksted ${ }^{21}$, Oslo, Noruega $^{22}$.

El buque, capitaneado por Andresen, llega a Punta Arenas a medio día del 30 de agosto, contando con el armamento necesario para la pesca de ballenas ${ }^{23}$. El Gobierno de Chile extenderá el 6 de noviembre de 1905 la patente de navegación a favor del vapor Almirante Montt de propiedad de los señores De Bruyne, Andresen i Cia., de Punta Arenas, i que mide cincuenta $i$ seis toneladas $i$ dos centésimas de toneladas de registro ${ }^{24}$ y su número en el Registro de la Marina Mercante será el $726^{25}$. El Almirante Montt aparece en dos fotografías de la colección del Archivo Iconógrafico del Instituto de la Patagonia (AI-IP; ver Figura 1 y 5).

Hay diferencias en las diversas fuentes respecto del tonelaje o, mejor dicho, arqueo de los buques. Se debe probablemente al uso de distintas unidades para medirlo. En el caso del Almirante Montt las fuentes noruegas hablan de 123 GRT y $23 \mathrm{NRT}^{26}$ y las chilenas de 113,25 toneladas

19 NHP [Nominal Horse Power] es una medida usada para estimar la potencia de los motores a vapor y depende del tamaño del motor y la velocidad de los pistones. IHP [Indicated Horse Power] es una medida de la potencia teórica de un motor a vapor si no existiera fricción al convertir el gas en expansión en energía en los cilindros.

20 PSI [pound per square inch] es una unidad para medir la presión (fuerza/superficie) y es una abreviatura de libras/ pulgada ${ }^{2}$.

21 Akers Mekaniske Verksted, astillero conocido como Akers, se encuentra ubicado a orillas del río Aker, en Oslo, Noruega. Comenzó sus actividades en 1841, produciendo una gran variedad de equipamiento mecánico para luego concentrarse en la construcción de buques balleneros, cargueros, tanqueros y de pasajeros, y de motores para estos buques (Lødrup 1951).

22 Las especificaciones técnicas del buque fueron obtenidas del registro noruego de embarcaciones Det Norske Veritas, correspondiente al año 1908.

23 El Comercio (Punta Arenas), 31 de agosto de 1905.

24 D.S. N ${ }^{\circ} 2901$ del 6 de noviembre de 1905. Decretos, Fondo Ministerio de Marina, volumen 1456. Archivo Nacional [Santiago de Chile]. También en Diario Oficial (Santiago de Chile), 13 de noviembre de 1905.

25 Lista Oficial de la Marina Mercante Nacional en 31 de diciembre de 1905. Memoria del Ministerio de Marina, 1905. Santiago: Nacional. 1906.

26 Det Norske Veritas, 1908.

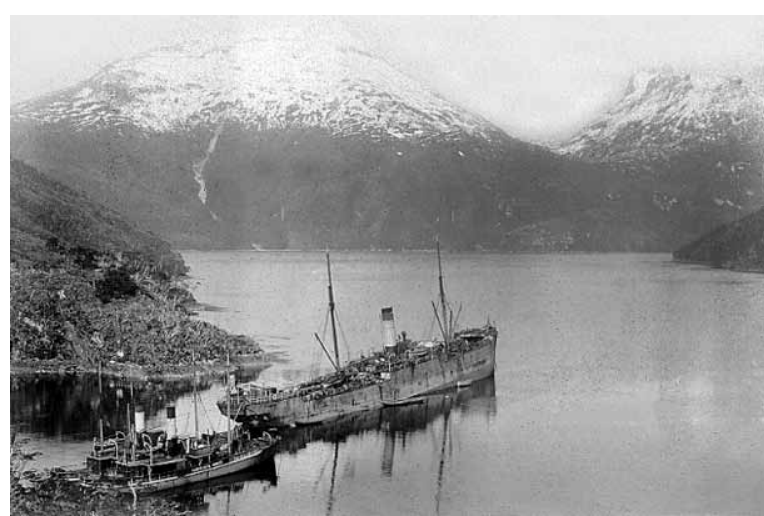

Fig. 1. Parte de la Flota ballenera anclada en bahía Águila. Se ven en primer plano el cazador Almirante Montt y el buque factoría Gobernador Bories. En un segundo plano y prácticamente tapado por el A. Montt, se observa otro de los cazadores, el Almirante Uribe o el Almirante Valenzuela

(Fotografía de E. B. Binnie, 1907. Archivo Fotográfico CEHA. Instituto de la Patagonia, Universidad de Magallanes).

gruesas y 56,02 toneladas de registro ${ }^{27}$. No tenemos claridad respecto de la equivalencia de estas medidas, pero las fuentes consultadas indican la presencia de un cierto grado de subjetividad en las mediciones: tanto el arqueo grueso como el neto dependen de las reglas bajo las cuáles son medidos y las reglas están lejos de ser uniformes; los arqueos gruesos y netos bajo distintas reglas no son exactamente comparables (Riegel 1921: 131). En la mayoría de los buques de la Sociedad Ballenera de Magallanes se presentan estas diferencias en el arqueo.

\section{La Sociedad Ballenera de Magallanes y la formación de la flota antártica}

La constitución de la Sociedad Ballenera de Magallanes en 1906 es un esfuerzo por ampliar los negocios de la la sociedad en comandita De Bruyne, Andresen \& Co., pues era indudablemente, una lástima continuar en pequeña escala un negocio que se presentaba bajo tan buenos auspicios (Braun 1985: 207). En los estatutos de la nueva sociedad se valora en $£ 30,000$ los bienes de la sociedad en comandita, formados por los terrenos, edificios, instalaciones, maquinarias,

27 Lista Oficial de la Marina Mercante Nacional en 31 de diciembre de 1905. Memoria del Ministerio de Marina, 1905. Santiago: Nacional, 1906. 
vapor ballenero i demás embarcaciones ${ }^{28}$, pero, sin duda, los bienes más relevantes eran el vapor Almirante Montt i el establecimiento de Bahía Águila (Navarro, op.cit.: 298c). Es un dato que no deja de ser interesante pues el capital inicial de la sociedad en comandita fue, como ya lo hemos señalado, de solo $£ 11,000$, por lo que se había prácticamente triplicado en un año. Esta ampliación significaba básicamente el inicio de la caza de ballenas en los mares antárticos.

El sistema de plantas terrestres no era muy conveniente para operar en aguas antárticas: el empresario naviero y ballenero noruego Chr. Christensen había creado un sistema que implicaba el uso de buques cazadores, que capturaban y remolcaban las ballenas, y el empleo de buques factoría que, fondeados cerca de la costa, las procesaban a bordo. El empresario naviero usaba sus astilleros de Framnæes, Sandefjord, para convertir y equipar los buques, especialmente vapores, en buques-factoría (Tønnessen y Johnsen op.cit.: 96; Bogen 1948). Chr. Christensen había probado el sistema en 1903 al enviar el Telegraf, buque de la A/S Ørnen a Spitsbergen, en el norte de Europa: esa era la primera vez, en el período de la caza moderna de ballenas, basada hasta ese momento en estaciones costeras terrestres, que se usaba un buque factoría combinado con buques cazadores (Adie y Basberg 2009: 243). El sistema será ocupado por primera vez en aguas antárticas en la temporada 1905/1906 por el buque factoría Admiralen y los cazadores Hauken y Ørnen que buscaban capturar ballenas en las aguas de las Islas Shetlands del Sur (Aagard 1930: 305; Adie y Basberg 2009).

Los socios envían a Noruega a nuestro amigo, socio y especialista, el capitán Andresen, reforzado con amplio crédito para adquirir las naves que fueran necesarias y adecuadas para la explotación ballenera (Braun 1985: 208) en aguas antárticas. Andresen encarga nuevamente a Framnæes la construcción de dos nuevos cazadores a vapor, que se denominarán, siguiendo la "tradición", Almirante Valenzuela y Almirante Uribe. Ambos buques fueron entregados durante el mes de octubre de 1906 (Bogen op.cit.: 333). Junto a

28 En D.S. N ${ }^{\circ}$ 2,905 [Ministerio de Hacienda], 7 de julio de 1906, Diario Oficial (Santiago de Chile), 27 de julio de 1906. estos buques la Sociedad Ballenera de Magallanes necesitaba además un buque que sirviera como factoría y otro de apoyo para el traslado de carbón y aceite. Andresen decide, entonces, adquirir el carguero Wordsworth, para prepararlo y usarlo como buque factoría, y el velero Anna Agnete, como transporte de apoyo.

El Almirante Valenzuela, número 62 de la lista del astillero, era un buque con casco de acero, de 93,3 pies de eslora, 19,0 pies de manga y 11,7 pies de puntal, con un tonelaje de 141 GRT y 54 NRT. Estaba equipado con un motor a vapor de triple expansión de tres cilindros, con una potencia de 59 NHP, alimentado por una caldera a carbón de 10,3×9,5 pies, con dos hornos de 39" de diámetro, que generaba vapor a 180 PSI. Tanto el motor como la caldera fueron construidos por Akers mek. Verksted, Oslo, Noruega. El Almirante Uribe, número 64 de la lista, también era un buque con casco de acero, pero algo más pequeño, pues medía 92,0 pies de eslora, 18,2 pies de manga y 11,1 pies de puntal, con un tonelaje de 126 GRT y 36 NRT. Estaba equipado con un motor a vapor de triple expansión, de tres cilindros, con una potencia de $52 \mathrm{NHP}$, alimentado por una caldera a carbón de 9,3×9,3 pies con dos hornos de 36" de diámetro, que generaba vapor a 180 PSI. El motor y la caldera fueron construidos también por Akers mek. Verksted, Oslo, Noruega ${ }^{29}$. Se conocen tres imágenes del Almirante Uribe: una la reproducimos en este trabajo (ver figura 2), y las otras se encuentran en las publicaciones de Ian Hart (2006: 72; 2009). En Hart (2006: 52) aparece una foto del Almirante Valenzuela junto al Telefon.

El Wordsworth era un vapor, con casco de hierro, construido en 1882 en los astilleros William Gray \& Co. Ltd., en West Hartlepool, Inglaterra (número 262) y entregado el 14 de octubre de ese año a la compañía Glover Bros, Londres Inglaterra, que lo usaría como carguero en el comercio de la India ${ }^{30}$. Su arqueo era de 2,055 GRT y 1,335 NRT y estaba equipado con un motor a vapor compuesto, de dos cilindros, con una potencia de $240 \mathrm{HP}$, construido por T. Richardson

29 Las características técnicas de los buques fueron obtenidas de Det Norske Veritas, 1908. Como en el caso del Almirante Montt hay diferencias en el arqueo de los buques.

30 The Marine Engineer, 1882, p. 220. 


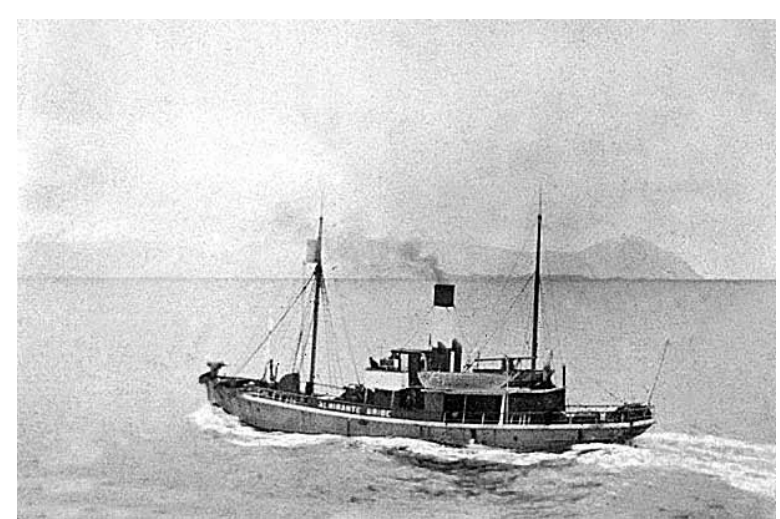

Fig. 2. El cazador Almirante Uribe navegando hacia aguas antárticas (Fotografía de E. B. Binnie, 1907. Archivo Fotográfico CEHA. Instituto de la Patagonia, Universidad de Magallanes).

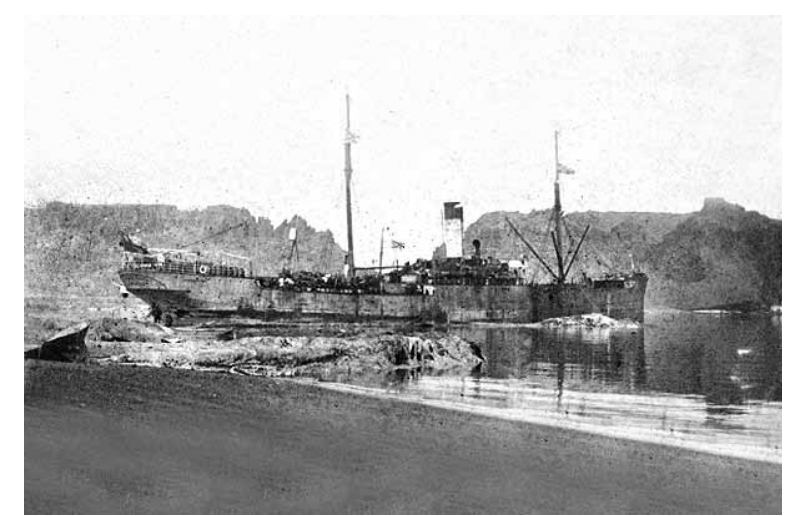

Fig. 3. El Gobernador Bories anclado en bahía Balleneros, Isla Decepción, Islas Shetlands del Sur, Antártica (Fotografía de E. B. Binnie, 1908. Archivo Fotográfico CEHA. Instituto de la Patagonia, Universidad de Magallanes).
\& Sons, de West Hartlepool, Inglaterra. Las dimensiones del buque eran de 285,7 pies de eslora, 34 pies de manga y 24,2 pies de puntal ${ }^{31}$. En 1906 fue adquirido por la Sociedad Ballenera de Magallanes y ese mismo año será modificado en los astilleros Framnaes para usarlo como buque factoría en la caza de ballenas (Bogen 1948: 234, 249-250), cambiando su nombre por el de Gobernador Bories. El Gobernador Bories aparece en varias fotografías de la colección del AI-IP (por ejemplo, ver Figuras 1 y 3).

El Anna Agnete, ex Margaret Heald, era un velero de acero, con una cubierta y tres arboladuras, construido en 1877 en los astilleros R. \& J. Evans \& Co., Liverpool, Inglaterra (número 76) y entregado el 12 de diciembre de ese mismo año a J.B. Foote, de Liverpool, Inglaterra. El arqueo del buque era de 631 GRT y 605 NRT. Sus dimensiones eran 173 pies de eslora, 29,2 pies de manga y 18,1 pies de puntal ${ }^{32}$. En 1882 fue adquirido por J. Heald, también de Liverpool, Inglaterra ${ }^{33}$. En 1889 fue vendido a C.H. Nielsen, Nordby, Fanø, Dinamarca y su nombre cambiado a Anna Agnete $e^{34}$. En abril de 1906 fue comprado en $£ 1175$ por la Sociedad Ballenera de Magallanes y rebautizado como Cornelia Jacoba, para usarlo como depósito de carbón para los 'catchers', y como

\footnotetext{
31 Lloyd's Register of British \& Foreign Shipping, 1883.

32 Lloyd's Register of British \& Foreign Shipping, 1877.

33 Lloyd's Register of British \& Foreign Shipping, 1883.

34 Lloyd's Register of British \& Foreign Shipping, 1889.
}

tanquero para almacenar el aceite (Braun 1985: 208). Podía cargar hasta 1200 toneladas de carbón. El Cornelia Jacoba aparece también en dos fotografías de la colección del AI-IP (ver figuras 4 y 5$)$.

El velero Cornelia Jacoba, "que viene para el servicio de la Sociedad Ballenera" desde Amberes, llega a Punta Dúngenes el 11 de agosto de 1906, siendo remolcado hasta Punta Arenas por el Almirante Montt ${ }^{35}$. Los vapores cazadores Almirante Valenzuela y Almirante Uribe y el buque factoría Gobernador Bories llegan juntos a Punta Arenas recién el 28 de noviembre de 1906 (Navarro, 1907: 298c).

El Gobierno de Chile extenderá las patentes de navegación respectivas a la barca a vela Cornelia Jacoba [...] que mide seiscientas cinco toneladas cincuenta i ocho toneladas de rejistro ${ }^{36}$, a los vapores Almirante Valenzuela, que mide setenta i cuatro toneladas veintidos centésimos de tonelada de rejistro y Almirante Uribe, que mide setenta toneladas i veinticuatro centésimos de rejistro ${ }^{37}$, y al buque factoría Gobernador Bories, que mide mil ochocientas quince toneladas $i$ ciencuenta $i$

El Comercio (Punta Arenas), 12 de agosto de 1906.

D.S. $N^{\circ} 2563$ [Ministerio de Marina], 27 de septiembre de 1906. Diario Oficial (Santiago de Chile), 16 de octubre de 1906.

37 D.S. N ${ }^{\circ} 695$ del 23 de abril de 1907. Decretos, Fondo Ministerio de Marina, volumen 1559. Archivo Nacional [Santiago de Chile., También en Diario Oficial (Santiago de Chile), 4 de mayo de 1907. 


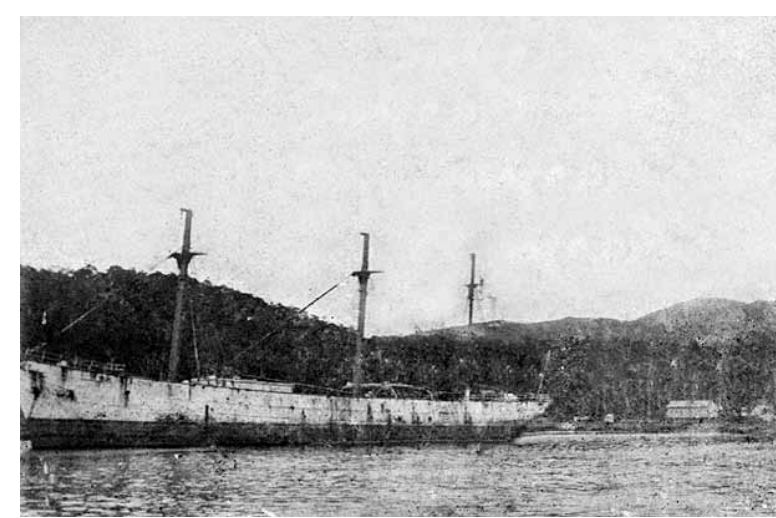

Fig. 4. El velero Cornelia Jacoba, anclado en bahía Águila (Fotografía de E. B. Binnie, 1907. Archivo Iconográfico Instituto de la Patagonia, Universidad de Magallanes). cuatro toneladas de rejistro ${ }^{38}$, entre 1906 y 1907. Sus números en el Registro de la Marina Mercante serán el 735 para el Cornelia Jacoba, el 784 para el Almirante Valenzuela, el 785 para el Almirante Uribe y el 787 para el Gobernador Bories ${ }^{39}$.

Con estos buques la Sociedad Ballenera de Magallanes estaba lista para comenzar a cazar ballenas en aguas antárticas. Durante la temporada 1906/1907 usará por primera vez el sistema en las Shetlands del Sur y lo seguirá haciendo por las siguientes siete temporadas, siendo la última la de 1913/1914. La sociedad A/S Corral, sucesora de la Sociedad Ballenera y Pescadora de Valdivia, lo hará en la temporada 1912/1913 en las Orcadas del Sur con el buque factoría Tioga y los cazadores Fyr y Corral (Headland 1989: 252).

\section{Buques para las operaciones}

en las Islas Guaitecas

La Sociedad Ballenera de Magallanes intenta instalar, además de las operaciones en los canales magallánicos y en aguas antárticas, una nueva faena ballenera, esta vez en la zona del golfo del Corcovado, al sur de Chiloé. En 1909 compra

D.S. $N^{\circ} 1066$ del 11 de junio de 1907. Decretos, Fondo Ministerio de Marina, volumen 1565. Archivo Nacional [Santiago de Chile], También en Diario Oficial (Santiago de Chile), 17 de julio de 1907.

39 Lista Oficial de la Marina Mercante Nacional en 31 de diciembre de 1907. Memoria del Ministerio de Marina. Santiago: Nacional, 1908.

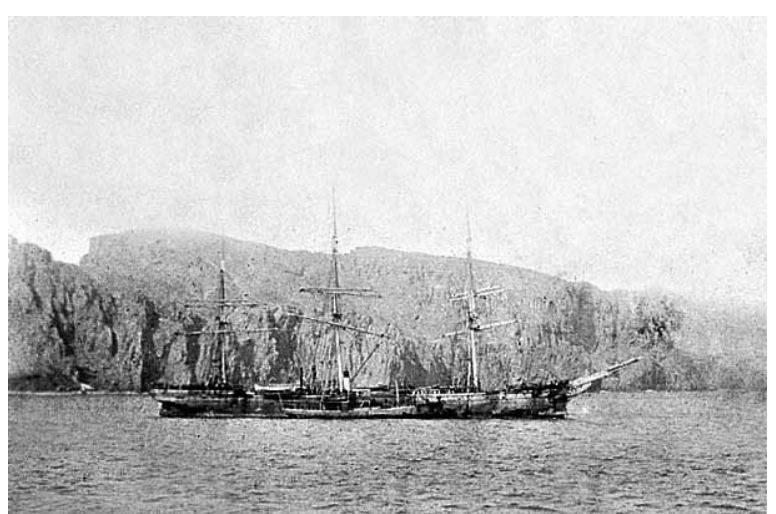

Fig. 5. El velero Cornelia Jacoba y el cazador Almirante Montt, anclados en bahía Balleneros, Isla Decepción, Islas Shetlands del Sur, Antártica (Fotografía de

E.B. Binnie, 1908. Archivo Iconográfico Instituto de la Patagonia, Universidad de Magallanes).

el buque-frigorífico Rubens, de la Lamport \& Holt Line, que, como se sabe, está desde hace tiempo fondeado en nuestra bahía [Punta Arenas] para instalar en él una fabrica flotante de aceite en la Isla de Chiloé, alegrando a la prensa regional que una firma local estienda sus negocios fuera del territorio, porque ello significa un progreso más para Magallanes ${ }^{40}$. En la $4^{\circ}$ Memoria de la Sociedad Ballenera de Magallanes se informa a los accionistas de la compra del pontón Rubens, buque que servirá de fábrica flotante como base de un nuevo centro de pesca en el Pacífico ${ }^{41}$. Además se decide adquirir un vapor cazador usado, el Naddoddur que operaba en Islandia, para acompañar al Rubens en las operaciones en Chiloé.

El Rubens era un buque de carga, a vapor, con casco de hierro, construido en 1872 por Illiff, Mounsey \& Co., de Sunderland, Inglaterra (número 58) y entregado el 20 de septiembre de ese año a Patton \& Co., Liverpool, Inglaterra. Su tonelaje era de 1708 GRT y 1265 NRT, con dos cubiertas y dos arboladuras, y su motor, de 140 HP, fue construido por Black \& Hawthorne, de Gateshead, Inglaterra. Las dimensiones del buque eran 270 pies de eslora, 32,5 pies de manga y 28, 8 pies de puntal ${ }^{42}$. En 1878 es vendido a la Lamport \& Holt Line para su Liverpool, Brazil \& River Plate Steam Navigation Co. Ltd., Liverpool,

Chile Austral (Punta Arenas), 2 de septiembre de 1909 Chile Austral (Punta Arenas), 9 de febrero de 1910. Lloyd's Register of British \& Foreign Shipping, 1873. Record of American \& Foreign Shipping, 1878. 
Inglaterra ${ }^{43}$. Desde el año 1901 la empresa lo había mantenido fondeado en Punta Arenas hasta que en 1909 la Sociedad Ballenera de Magallanes lo compra en $£ 500$, siendo remolcado, en octubre de ese año, a bahía Águila por el Almirante Montt y el Almirante Valenzuela ${ }^{44}$. El Rubens fue equipado para el procesamiento de las ballenas pues más tarde se diría que tiene a bordo las siguientes instalaciones para beneficiar ballenas: máquina a vapor horizontal de $\mathrm{m} / \mathrm{m} 12 \mathrm{HP}$; cuchillos de rotación; elevador; 3 digestores cilíndricos de $\mathrm{m} / \mathrm{m} 11$ toneladas c/u; 2 digestores de presión (uno de ellos no montado) de 3,30 × 2,10 y de 4,00 × 2,50 (medida exterior y aproximada); 10 estanques rectangulares de $\mathrm{m} / \mathrm{m} \mathrm{3} / 4$ hasta 15 toneladas c/u; dos bombas a vapor; $2 \mathrm{~m} / \mathrm{m} 188 \mathrm{me}$ tros de cañería 45 .

El Almirante Señoret, ex Naddoddur, había sido construido por Nylands mek. Verksted ${ }^{46}$, Oslo, Noruega, número 169, y entregado el 23 de marzo de 1906 a la empresa A/S Skjaersnaess, dirigida por Hans Ellefsen, de Stokke, cerca de Tonsberg, Noruega, que poseía la estación terrestre de Askness, en Mjoafjord, Islandia (Sigurjónsson y Gunnlaugsson 2006) ${ }^{47}$. Era un vapor con casco de acero, con un tonelaje de 110 GRT y 56 NRT, de 87,3 pies de eslora, 17,5 pies de manga y 11,7 pies de puntal. No tenemos información sobre el motor y las calderas del buque. Fue adquirido en 1910 por la Sociedad Ballenera de Magallanes. La primera campaña de cacería de ballenas registrada del Almirante Señoret corresponde la temporada antártica 1910/191 y luego durante el mes de marzo de 1911 se dirige a la zona de Chiloé ${ }^{48}$

44 El Comercio (Punta Arenas), 15 de octubre de 1909.

45 La Unión (Punta Arenas), 14 de noviembre de 1916.

46 Nylands Mekaniske Verksted, astillero situado en la ribera del Aker, en Bjorvika, Oslo, Noruega, fue fundado en 1855. Nylands era, a comienzos del siglo XX, el astillero más grande del país, con más de mil empleados. Fue adquirido en 1956 por Aker Mekaniske Verksted (http://www.lardex. net/nylandsverksted/historien.htm; consultado el $21 \mathrm{de}$ enero del 2011).

47 Gracias a la información entregada gentilmente por Sigúr Dögg Kvaran, del Hafrannsóknastofnunin [Instituto de Investigaciones Marinas] de Reykjavik, Islandia, sabemos que entre abril de 1906 y septiembre de 1909, el Naddoddur capturó un total de 178 ejemplares, siendo sus capitanesarponeros C. Andersen [1906-1908] y P.A. Rismyrh [1909], quién lo lleva de vuelta a Tonsberg, Noruega.

48 El Comercio (Punta Arenas), 23 de marzo de 1911. para operar con el Rubens, fábrica flotante, actualmente [está] en Guaytecas ${ }^{49}$.

A fines de ese año la sociedad adquiere por intermedio de A. Andresen, el velero alemán Nixe, renombrado Wilhelmine para operar en las Guaitecas en reemplazo del Rubens. El Rubens será usado desde mediados de 1912 como pontón en bahía Águila, para el depósito de mercaderías, aceite y carbón ${ }^{50}$.

La barca Nixe había sido construida en los astilleros Bremer SG, de Vegesack, Alemania, en 1887, con 1719 GRT y 1672 NRT. Las dimensiones del buque eran 228 pies de eslora, 39 pies de manga y 24 pies de puntal. Según nuestros datos, en 1896 su propietario era Gildemeister \& Rius, de Bremen, Alemania ${ }^{51}$ y en 1898 era la empresa Rhederei Visurgia AG, también de Bremen, habiendo modificado su arqueo a 1686 GRT y 1553 NRT $^{52}$.

El Gobierno de Chile extenderá patente de navegación a favor del vapor Almirante Señoret de propiedad de la Sociedad Ballenera de Magallanes, que mide cincuenta i cinco toneladas $i$ dieciseis centésimos de toneladas de registro ${ }^{53} \mathrm{y}$ su matrícula en el Registro de Buques Mercantes chilenos será la $\mathrm{N}^{\circ} 845^{54}$. Ni al Rubens ni al Wilhelmine se les extenderá patente de navegación

49 Memoria del Ministerio de Marina, 1911, Fondo Ministerio de Marina, volumen 1812. Archivo Nacional [Santiago de Chile].

50 En noviembre de 1912 el Rubens tiene un accidente en bahía Águila, cuando es chocado por el Gobernador Bories, durante una tormenta causando al pontón una seria avería de importancia por la cual penetró el agua abundantemente" pero "los encargados de las faenas del establecimiento ballenero [...] hicieron los trabajos consiguientes para conducir a la playa el pontón, lo que obtuvieron logrando además salvar la carga que tenía a su bordo. La opinión generalizada era que, en realidad, nada pierde la compañía pues el Rubens no era en absoluto necesario y si se le tenía en servicio era por ofrecer mayor comodidad. La mercadería que en él era depositada pasará a serlo en tierra en donde hay galpones cómodos para el objeto Chile Austral (Punta Arenas), 12 de noviembre de 1912.

51 Lloyd's Register of British \& Foreign Shipping, 1896.

52 Lloyd's Register of British \& Foreign Shipping, 1898.

53 D.S. $N^{\circ} 1678$ del 29 de noviembre de 1910. Decretos, Fondo Ministerio de Marina, Archivo Nacional [Santiago de Chile], volumen 1749. También en Diario Oficial (Santiago de Chile), 19 de diciembre de 1910.

54 Naves mercantes ingresadas al Registro de la Marina Mercante Nacional el año 1910. Memoria del Ministerio de Marina, 1910, Fondo Ministerio de Marina, volumen 1766, Archivo Nacional [Santiago de Chile]. 
y tampoco serán ingresados en el Registro de la Marina Mercante de Chile.

\section{La adquisición del Telefon}

Es necesario mencionar que la Sociedad Ballenera de Magallanes adquiere en 1910, en un remate público por la suma de £925 el vapor Tele$f^{5}{ }^{55}$, que había naufragado el 26 de diciembre de 1908 a la entrada de la bahía del Almirantazgo, en la isla San Jorge, Shetlands del Sur, al chocar con un arrecife no registrado en las cartas náuticas (Charcot 1911: 255; Heyburn y Stenersen op.cit.. 51). El Telefon era un buque de carga, a vapor, con casco de hierro, construido en 1899 por Wood, Skinner \& Co, Newcastle on Tyne, Inglaterra (número 87) para P.A. Grøn, de Sandefjord, Noruega ${ }^{56}$. Su arqueo era de 1538 GRT $^{57}$. Estaba equipado con un motor a vapor de triple expansión, con una potencia de 138 $\mathrm{hp}^{58}$. Sus dimensiones eran $77 \mathrm{~m}$ [255 pies] de eslora, $11 \mathrm{~m}$ [36 pies] de manga y $5 \mathrm{~m}$ [16 pies] de puntal (Heyburn y Stenersen 1989: 51) ${ }^{59}$. En 1908 había sido arrendado por Chr. Christensen como buque carguero de apoyo que llevaba carbón, barriles vacíos y comida fresca para su flota ballenera que operaba en las islas Shetlands del Sur ${ }^{60}$.

55 El Comercio (Punta Arenas), 24 de mayo de 1910.

56 The Marine Engineer, 1900; pp. 452, 522, 561.

57 Dato obtenido en www.miramarshipindex.org.nz (consultado el 23 de julio del 2010). Hay diferencias en las distintas fuentes respecto del arqueo del buque. Heyburn \& Stenersen hablan de 2300 ton (op.cit.: 51) pero en los avisos de remate del buque aparecen tanto 1385 GRT (Chile Austral [Punta Arenas], 12 de marzo de 1910) como 1830 GRT (Chile Austral [Punta Arenas], 14 de mayo de 1910).

58 Este dato fue obtenido de los avisos de remate del buque publicado en el Chile Austral (Punta Arenas), el 12 de marzo de 1910 y el 14 de mayo de 1910.

59 Hay diferencias en las diversas fuentes respecto de las dimensiones del buque: en el Chile Austral (Punta Arenas) del 12 de marzo de 1910 se indica que sus medidas eran 264x36x15 pies y en el del 14 de mayo de 1910, 264×36x25 pies (eslora/manga/puntal).

60 En un trabajo muy interesante Heyburn \& Stenersen (1989: 51-54) abordan el naufragio y salvamento del Telefon, usando principalmente los testimonios de Charcot, testigo de las maniobras, los trabajos de un grupo de historiadores noruegos (Risting 1922, Aagaard 1930, Bøgen 1953 y Tønnesen y Johnsen 1982), el diario del buque ballenero Grib y las noticias publicadas el Sandefjords Blad sobre el accidente y rescate del buque. Nosotros aportaremos, en esta oportunidad, la información entregada por la prensa magallánica, principalmente el Chile Austral (Punta Arenas).
El buque fue rescatado por la flota antártica de la sociedad: aunque se cree fácil salvarlo, tiene el doble fondo, departamento de máquina i bodega de popa completamente inundados, pues se abrió una gran vía al chocar en una roca sumergida [pero toda la tripulación] compuesta de 19 personas, el capitán y un pasajero se salvaron en bote llegando a la bahía Decepción ${ }^{61}$. Andresen relatará a los diarios magallánicos que el ballenero Almirante Valenzuela, ayudado por los otros balleneros chilenos, Almirante Montt y Almirante Uribe remolcaron el Telefon hasta la isla Decepción [llegando allí] el 29 de diciembre. Los mismos balleneros más el Gobernador Bories, barco que llegó después, trataron de reparar el Telefon y traerlo a Punta Arenas, lo que no resultó posible por la falta de bomba, buzo $y$ otros elementos [...por lo que] vararon el Telefon en la playa de isla Decepción [y...] la tripulación de la barca fue recogida en parte por los balleneros noruegos que llevaban rumbo a las Malvinas y el resto por otros barcos noruegos y algunos chilenos. Con la flotilla chilena llegaron aquí seis personas de la tripulación del Telefon incluso el capitán del mismo Roland Nielsen ${ }^{62}$. El 30 de octubre de 1909 zarpa la flotilla ballenera desde Bahía Águila en su expedición antártica anual, esta vez llevando tripulantes y elementos para completar el salvamento del vapor Telefon y a su regreso traerlo a Punta Arenas ${ }^{63}$. El 23 de febrero de 1910 llega a Punta Arenas el vapor Almirante Valenzuela de la Sociedad Ballenera de Magallanes, remolcando el vapor noruego Telefon, también ballenero encallado tiempo atrás en las islas Shetlands ${ }^{64}$, fondeado posteriormente en bahía Águila ${ }^{65}$. El Telefon no es utilizado en actividades balleneras pero igualmente fue registrado en la Marina Mercante Nacional con el número $839^{66}$ y vendido ese mismo año ${ }^{67}$.

Chile Austral (Punta Arenas), 14 de marzo de 1909.

El Comercio (Punta Arenas) 15 de marzo de 1909.

Chile Austral (Punta Arenas9, 29 de octubre de 1909.

Chile Austral (Punta Arenas), 23 de febrero de 1910.

El Comercio (Punta Arenas), 9 de marzo de 1910.

Naves mercantes ingresadas al registro de la Marina Mercante Nacional en el año 1910. Memoria del Ministerio de Marina, 1910, Fondo Ministerio de Marina, volumen 1766. Archivo Nacional [Santiago de Chile].

67 Nómina de las transferencias efectuadas en el registro de la Marina Mercante Nacional en el año 1910. Memoria del Ministerio de Marina, 1910, Fondo Ministerio de Marina, volumen 1766. Archivo Nacional [Santiago de Chile]. 
La "nueva” Sociedad de Magallanes y los últimos buques de la flota ballenera

Entre las preocupaciones de la "antigua" Sociedad Ballenera de Magallanes estaba la adquisición de nuevos buques, tanto cazadores como también factorías y transportes. Es así como en 1910 habían encargado a los astilleros Framnaes la construcción de un cazador nuevo, llamado Almirante Goñi, que debido a la alta demanda de estos vapores será entregado recién en 1912.

El Almirante Goñi, era un buque nuevo, construido por Framnæes mek. Verksted, Sandefjord, Noruega, con el número 88 , que fue entregado durante el mes de enero de 1912, arribando a Punta Arenas, no sin dificultades ${ }^{68}$, a fines de febrero de ese año. Era un vapor con casco de acero, con un arqueo de 167 GRT y 57 NRT, con 110,3 pies de eslora, 20,1 pies de manga y 11,8 pies de puntal. Estaba equipado con un motor a vapor de triple expansión, de tres cilindros, con una potencia de $84 \mathrm{NHP}$, alimentado por una caldera a carbón de 11,5×11 pies, con dos hornos de 46,3" de diámetro, que generaba vapor a 200 PSI. Tanto el motor como la caldera fueron construidos por Akers mek. Verksted, Oslo, Noruega ${ }^{69}$.

La primera misón del Almirante Goñi, que llega a Punta Arenas en febrero de 1912, será remolcar la barca Wilhemine, adquirida por la Sociedad Ballenera de Magallanes para potenciar la posibilidad de instalar en Chiloé un nuevo centro de operaciones balleneras. Salen el 14 de marzo de Punta Arenas, pero la barca naufraga 10 días después y el Almirante Goñi regresa a Punta Arenas. El Gobierno de Chile extenderá la patentes de navegación a favor del vapor Almirante Goñi [...], que mide ochenta i cinco tonelaedas i ciencuenta i cinco centésimos de tonelada de rejistro ${ }^{70}$ y será inscrito en el registro de la Marina Mercante con

68 Uno de sus tripulantes, Ole A. Clementz, cuenta, muchos años después, algunas de las dificultades experimentadas por el Almirante Goñi en su viaje inicial a Punta Arenas. Sandefjord Blad (Sandefjord, Noruega), 5 de junio de 1963.

69 Det Norske Veritas, 1913.

70 D.S. $N^{\circ} 795$ del 10 de junio de 1912. Decretos, Fondo Ministerio de Marina, volumen 1830. Archivo Nacional [Santiago de Chile]. el número 87671. El Almirante Goñí participará en las campañas antárticas de 1912-1913 y 19131914, las últimas en las Shetlands del Sur de la Sociedad Ballenera de Magallanes.

La "nueva" Sociedad Ballenera de Magallanes además realizará diversas gestiones en Inglaterra para cambiar el buque factoría, pues al Gobernador Bories se lo consideraba demasiado pequeño para las necesidades de la empresa ${ }^{72}$. Es así como en 1914 se adquiere un "nuevo" buque para adaptarlo como buque factoria, es el Senator, y que como el viejo 'Gobernador Bories' será probablemente vendido, el nuevo vapor conservará el mismo nombre ${ }^{73}$. Comprado en $£ 13,800$ por la Sociedad Ballenera de Magallanes, a través de los oficios de Duncan, Fox \& Co, será modificado en Noruega por unas $£ 10,000$ adicionales ${ }^{74}$, para instalarle a bordo los tanques para almacenar el aceite de ballena y los digestores para preparar el mismo ${ }^{75}$ y así poder usarlo como buque factoría en la caza de ballenas. La Sociedad Ballenera de Magallanes tendrá entonces un ballenero de primera clase $^{76}$. El buque tiene una capacidad necesaria para contener hasta cuatro mil toneladas de aceite $e^{77}$.

El Gobernador Bories II, ex Senator, era un buque a vapor construido en 1893 en los astilleros Workman, Clark \& Co, de Belfast, Irlanda del Norte (número 95), para T. \& J. Harrison, Liverpool. Inglaterra. El arqueo del buque era de 4,689 GRT y 3,049 NRT y sus dimensiones 400'3" de eslora, $45^{\prime} 3$ " de manga y 29'8" de puntal ${ }^{78}$. Estaba equipado con un motor a vapor, de triple expansión, de tres cilindros de 25", 41" \& 68"-54", con una potencia de $430 \mathrm{NHP} / 2350 \mathrm{IHP}$, construido por Workman, Clark \& Co, Belfast, Irlanda del Norte $e^{79}$.

71 Naves mercantes ingresadas al Registro de la Marina Mercante Nacional el año 1912. Memoria del Ministerio de Marina, 1910, Fondo Ministerio de Marina, volumen 1860, Archivo Nacional [Santiago de Chile]

72 La Unión (Punta Arenas), 12 de enero de 1914.

73 La Unión (Punta Arenas), 14 de junio de 1914.

74 Duncan, Fox \& Co. a Moritz Braun, Londres, 25 de junio de 1914. Correspondencia Recibida, Archivo Braun Menéndez, Museo Regional de Magallanes.

75 La Unión (Punta Arenas), 14 de junio de 1914.

76 Duncan, Fox \& Co. a Moritz Braun, Londres, 25 de junio de 1914. Correspondencia Recibida, Archivo Braun Menéndez, Museo Regional de Magallanes.

77 Chile Austral (Punta Arenas), 5 de marzo de 1915.

78 The Marine Engineer, 1893, pp. 437, 489.

79 Lloyd's Register of British \& Foreign Shipping, 1923-24. 
Tabla 1. La flota de la sociedad ballenera de Magallanes (1905-1916).

\begin{tabular}{|l|ccccccccccccc|l|l|}
\hline & 1905 & 1906 & 1907 & 1908 & 1909 & 1910 & 1911 & 1912 & 1913 & 1914 & 1915 & 1916 & \\
\hline Almirante Montt & $\mathrm{X}$ & $\mathrm{X}$ & $\mathrm{X}$ & $\mathrm{X}$ & $\mathrm{X}$ & $\mathrm{X}$ & $\mathrm{X}$ & $\mathrm{X}$ & $\mathrm{X}$ & $\mathrm{X}$ & $\mathrm{X}$ & $\mathrm{X}$ & Vendido en Italia \\
Almirante Uribe & & $\mathrm{X}$ & $\mathrm{X}$ & $\mathrm{X}$ & $\mathrm{X}$ & $\mathrm{X}$ & $\mathrm{X}$ & $\mathrm{X}$ & $\mathrm{X}$ & $\mathrm{X}$ & $\mathrm{X}$ & $\mathrm{X}$ & Vendido en Italia \\
Almirante Valenzuela & & $\mathrm{X}$ & $\mathrm{X}$ & $\mathrm{X}$ & $\mathrm{X}$ & $\mathrm{X}$ & $\mathrm{X}$ & $\mathrm{X}$ & $\mathrm{X}$ & $\mathrm{X}$ & $\mathrm{X}$ & $\mathrm{X}$ & Vendido en Italia \\
Gobernador Bories (1) & & $\mathrm{X}$ & $\mathrm{X}$ & $\mathrm{X}$ & $\mathrm{X}$ & $\mathrm{X}$ & $\mathrm{X}$ & $\mathrm{X}$ & $\mathrm{X}$ & $\mathrm{X}$ & & & Vendido en Inglaterra \\
Cornelia Jacoba & & $\mathrm{X}$ & $\mathrm{X}$ & $\mathrm{X}$ & $\mathrm{X}$ & $\mathrm{X}$ & $\mathrm{X}$ & $\mathrm{X}$ & $\mathrm{X}$ & $\mathrm{X}$ & $\mathrm{X}$ & $\mathrm{X}$ & Vendido en Chile \\
Rubens & & & & & $\mathrm{X}$ & $\mathrm{X}$ & $\mathrm{X}$ & $\mathrm{X}$ & $\mathrm{X}$ & $\mathrm{X}$ & $\mathrm{X}$ & $\mathrm{X}$ & Vendido en Chile \\
Telefon & & & & & & $\mathrm{X}$ & & & & & & & Vendido en Inglaterra \\
Almirante Señoret & & & & & & $\mathrm{X}$ & $\mathrm{X}$ & $\mathrm{X}$ & $\mathrm{X}$ & $\mathrm{X}$ & & & Vendido en Chile \\
Wilhelmine & & & & & & & & $\mathrm{X}$ & & & & & Naufragó en Chile \\
Almirante Goñi & & & & & & & & $\mathrm{X}$ & $\mathrm{X}$ & $\mathrm{X}$ & $\mathrm{X}$ & $\mathrm{X}$ & Vendido en Noruega \\
Gobernador Bories (2) & & & & & & & & & & & & & & & \\
\hline Total & 1 & 5 & 5 & 5 & 6 & 8 & 7 & 9 & 8 & 8 & 7 & 7 & \\
\hline
\end{tabular}

T. \& J. Harrison lo usa en su empresa Charente Steamship Co. Ltd., Liverpool, Inglaterra. El 7 de marzo de 1915 fondea en Punta Arenas el vapor 'Gobernador Bories' adquirido recientemente para la Sociedad Ballenera de Magallanes [...] tiene una tripulación de 44 individuos y viene al mando del capitán Sr. E. Olsen ${ }^{80}$.

El Gobierno de Chile extenderá patente de navegación a favor del vapor Gobernador Bories [...] que mide tres mil ventiun toneladas i sesenta i cinco centésimas de tonelada de rejistro ${ }^{81}$ y será inscrito en el registro de la Marina Mercante con el número $922^{82}$ De acuerdo a los antecedentes que manejamos, el Gobernador Bories II no alcanzó a participar en una expedición ballenera, pues llegó en 1915, fecha en la que la Sociedad Ballenera de Magallanes había decidido no realizar la campaña antártica. Las fuentes oficiales indican que no ha habido campaña de pesca durante el presente año [1915] debido a la crisis de la guerra europea. El vapor "Bories" está fletado i los otros vapores permanecen fondeados en bahía Águila ${ }^{83}$.

En la Tabla 1 mostramos el tamaño de la flota de la Sociedad Ballenera de Magallanes en-

80 Chile Austral (Punta Arenas), 8 de marzo de 1915.

81 D.S. N ${ }^{\circ} 375$ del 31 de marzo de 1915. Decretos, Fondo Ministerio de Marina, volumen 1987. Archivo Nacional [Santiago de Chile].

82 Naves mercantes ingresadas al Registro de la Marina Mercante Nacional en el año 1915. Memoria del Ministerio de Marina, 1910, Fondo Ministerio de Marina, volumen 2042, Archivo Nacional [Santiago de Chile].

83 Memoria del Ministerio de Marina, 1915. Fondo Ministerio de Marina, volumen 2402. Archivo Nacional [Santiago de Chile]. tre 1905 y 1916, considerando las adquisiciones y ventas realizadas durante el período.

\section{EL FUNCIONAMIENTO DE LA FLOTA}

La Sociedad Ballenera de Magallanes desarrollará sus actividades desde una planta terrestre, bahía Águila, y dos buques factoría, Gobernador Bories para las operaciones en la Antártica, y Rubens, para las de Chiloé. Estas actividades se van implementando secuencialmente, es decir, primero se opera desde bahía Águila y luego se van incorporando las actividades en aguas antárticas y luego en los canales patagónicos al sur de Chiloé.

La caza de ballenas en los canales magallánicos

La prensa regional registra el 26 de octubre de 1905 como la fecha de la primera captura realizada en la zona: De San Isidro se comunicó ayer que el vapor ballenero 'Almirante Montt' efectuó la pesca de dos ballenas en los canales, las que han sido varadas en un lugar conveniente, próximo al establecimiento construido para su beneficio $^{84}$. El día 16 de noviembre de 1905 el buque completa su primera docena de ballenas cazadas en los canales magallánicos ${ }^{85}$ y durante la primera quincena de diciembre se envían en el vapor Victoria, consignados a una casa comercial de Valpa-

84 El Comercio (Punta Arenas), 27 de octubre de 1905

85 El Comercio (Punta Arenas), 18 de noviembre de 1905 
raíso, los primeros 60 barriles de aceite de ballena elaborados en la planta terrestre de bahía Águila ${ }^{86}$.

Debido a las diversas actividades de Andresen somo gestor de la sociedad en comandita, a fines de 1905 queda al mando del Almirante Montt el capitán Gunnar Olsen, un verdadero sabueso de mar, que olfatea los codiciados cetáceos a través de cabos i promontorios. Bajo su comando, lleva a la planta de bahía Águila el 31 de diciembre de 1905 seis hermosas ballenas a remolque, y el 5 de enero de 1906 volvió al fondeadero con otros siete cetáceos. La prensa estima que toda esta pesca, que ya podría alcanzar el título de milagrosa, ha sido efectuada en aguas del estrecho $i$ sus vecindades. Sus resultados auguran un porvenir espléndido a la Sociedad Ballenera De Bruyne, Andresen y $\mathrm{Cia}^{87}$.

Durante los primeros días de mayo de 1906 la prensa magallánica señala que la cifra de ballenas harponeadas i beneficiadas desde el 2 de noviembre del año pasado hasta la fecha [es de] ciento veintitrés, entre las cuáles se han contado algunas de tamaño colosal, agregando que esta pesca puede calificarse de estraordinaria, podríamos aun decir milagrosa, si se considera que ha sido efectuada por un solo vapor, el Almirante Montt ${ }^{88}$.

En febrero o marzo de 1906 la planta de bahia Águila recibe la visita del periodista inglés H.A. Broome ${ }^{89}$, quién entrega un relato breve $e^{90}$ pero muy interesante sobre el mundo de la cacería de ballenas, el "deporte de los reyes", describiendo tanto los procesos que ocurren en la planta de procesamiento, el "lado prosaico" de la indusrtria ballenera, donde la captura propiamente tal sería, parafraseándolo, su "lado heroico". El periodista tuvo la oportunidad de participar en una campaña gracias a una invitación del capitán del Almirante Montt Gunner Olsen (Broome 1913: 296).

86 El Comercio (Punta Arenas), 13 de diciembre de 1905.

87 El Comercio (Punta Arenas), 5 de enero de 1906.

88 El Comercio (Punta Arenas), 1 de mayo de 1906.

89 Henry Arthur Broome (1856-1926). Nace en Norfolk, Inglaterra, en 1856. Tuvo muchas ocupaciones a lo largo de su vida, siendo una de ella fue la de reportero, oficio que ejerció en Sudáfrica, donde residió por varios años, Australia, Argentina y Chile (fue corresponsal en 1906 del Daily Mail en Punta Arenas). Escribió un libro con relatos de sus viajes (Broome 1913). Muere en Cheltenham, Inglaterra, en 1926.

90 La traducción desde el inglés de los párrafos citados del libro de Broome fue realizado por el autor de este trabajo.
Cuarenta millas al oeste de Punta Arenas, bajo el cabo Froward y cerca del faro San Isidro, se encuentra una pequeña bahía sin litoral, encerrada, excepto hacia el mar, por cerros cubiertos de nieve e impenetrables bosques sumergidos en las orillas del mar. Es conocida como Bahía Águila. Aquí, la Sociedad Ballenera de Magallanes ha retirado los árboles podridos cubiertos de musgos y la húmeda maleza para construir una planta terrestre para procesar el aceite de ballena. Un varadero equipado con winches a vapor y cables de cadenas, se inclina en una suave pendiente hacia arriba desde el agua y en él las ballenas muertas son arrastradas hasta las paredes de la fábrica. Los hombres cortan con afilados instrumentos la carne de los animales en piezas de diez pies de largo y un pie de grosor, que son levantados por un gancho y soltados en la parte superior de la fábrica, donde se deslizan por un enorme canal de madera en cuya base cuchillos rotatorios cortan cada trozo en pequeños pedazos que luego caen en grandes digestores de vapor en cuyo fondo hay una abertura donde el aceite es envasado en barriles para su envío. Uno se acostumbra a la carnicería diaria, pero nunca al enfermante olor que emana de la misma bahía, donde toda la basura se tira y las carcasas desnudas de años anteriores flotan y se niegan a hundirse (Broome 1913: 295-296).

Broome señala que como el Almirante Montt fue diseñado para perseguir, matar y remolcar estos mamíferos a la planta terrestre de bahía Águila, el buque estaba muy limpio, sin huellas de la presencia de ballenas. En la proa, en una plataforma levantada, se instalaba un cuasimortero o cañón, montado sobre un dispositivo giratorio, y terminado en una pistola. Tomando la culata de la pistola, el arponero podía estar detrás de su arma, seguro de un retroceso muy corto, y así apuntar rápido con el tiempo más malo, y si en un momento era necesario, podía modificar su trayectoria (Broome 1913: 297). Debajo de la boca del cañón, fuera de la borda, ocupando la posición donde normalmente iría el mascarón de proa de un barco, había una pequeña plataforma sobre la que estaban enrolladas, [...] muchas brazas de la cuerda de cáñamo mencionada. Estaba conectada a una cadena, que entraba por la boca del cañón y se sujetaba con un pivote al centro 


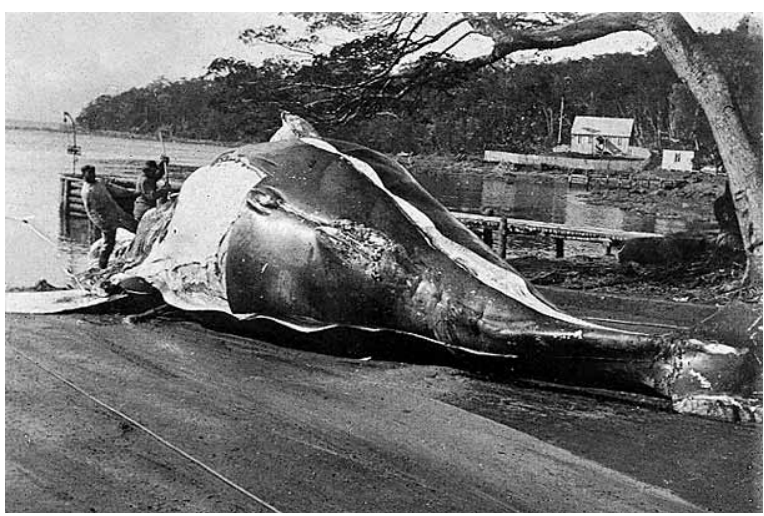

Fig. 6. El procesamiento de las ballenas en la planta de bahía Águila. (Fotografía de E. B.

Binnie, 1907. Archivo Iconográfico Instituto de la Patagonia, Universidad de Magallanes).

dentro del arpón y también se insertaba en la boca de la pistola, con el explosivo en su recámara (Broome op.cit.: 297). Si el arponero logra un disparo exitoso, se baja de inmediato un bote de los pescantes del vapor, llevando consigo largos rollos de manguera de plástico conectada con el motor del barco y armados en su otro extremo con un tubo de metal de boca afilada. Este se hunde en el lado de la ballena capturada, y se bombea aire en su intestino para evitar su hundimiento. El mamífero se deja inflado sobre las olas, con banderolas que dan cuenta exacta de su paradero, y en el viaje de regreso es recogido $y$ remolcado a la fábrica en la costa. A veces cuatro o cinco ballenas son llevadas lentamente a bahía Águila, el viaje dura diez días a dos semanas. Si el disparo falla y la ballena huye y no es bueno pero si se sumerge es mucho peor, porque si no está herida de muerte, ingresa abajo en las profundidades más grandes, llevándose con ella la reputación del tirador (Broome op.cit.: 297).

El periodista señala que Olsen era un tirador de primera y tenía que serlo porque si fallaba o le daba a la ballena y huía o se hundía, corría el riesgo no sólo de perder la ballena sino también un valioso arpón y una cantidad indefinida de la más fina cuerda de cáñamo, con un valor de al menos nueve libras, para no decir nada del bono que recibía de una libra por cada ballena capturada (Broome, op.cit.: 295).

En 1906, mientras llegaban los nuevos buques, el Almirante Montt continuaba sus correrías en los canales magallánicos. En la Primera Memoria i Balance de la Sociedad Ballenera de Magallanes presentada a los accionistas en diciembre de 1906 se da cuenta de que hasta el 28 de septiembre de ese año el vapor Almirante Montt había cazado 52 ballenas que fueron beneficiadas en bahía Águila, indicando que la producción alcanzaba las 149 toneladas de aceite, 40 de las cuáles se habían enviado a Europa, 10 toneladas de barbas i unas 1000 toneladas de huesos, más menos (Navarro 1907: 298c). El Almirante Montt continuará cazando ballenas ya sea en el estrecho de Magallanes mismo o en los mares cercanos a su desembocadura ya fuera del Atlántico, el Pacífico o el Pasaje de Drake (Braun 1985: 207), luego de la partida de la flotilla antártica. Es así como en enero de 1907 se informa que se dirige el miércoles a San Isidro, trayendo un cargamento de cuatro ballenas para el establecimiento de Bahía Águila ${ }^{91}$. El Almirante Montt había capturado setenta y nueve ballenas francas en el verano de 1907, en la boca occidental del estrecho de Magallanes (Tønnesen y Johnsen 1982: 175) $y$, considerando todas las especies en las distintas áreas de captura, un total de 106 ballenas (Tønnesen 1967, 2: 411).

Estas operaciones en los canales magallánicos continuarán con la llegada de otros vapores de la flotilla, los que después de volver en marzo de las Shetlands del Sur, acompañarán al Almirante Montt en sus cacerías en aguas magallánicas. Por ejemplo, durante el mes de abril de 1907 se informa que el Almirante Valenzuela anoche fondeó en la bahía, [...] remolcando seis hermosas ballenas, las que serán llevadas a San Isidro ${ }^{92}$.

\section{La caza de ballenas en aguas antárticas}

Con la llegada en 1906 del buque factoría Gobernador Bories el pontón Cornelia Jacoba y los cazadores Almirante Uribe y Almirante Valenzuela, la Sociedad Ballenera de Magallanes estará en condiciones de opera en "aguas antárticas" durante el verano meridional.

Los buques, apenas llegados a Punta Arenas, se preparan para la primera expedición a

91 El Comercio (Punta Arenas), 25 de enero de 1907.

92 El Comercio (Punta Arenas), 25 de abril de 1907. 


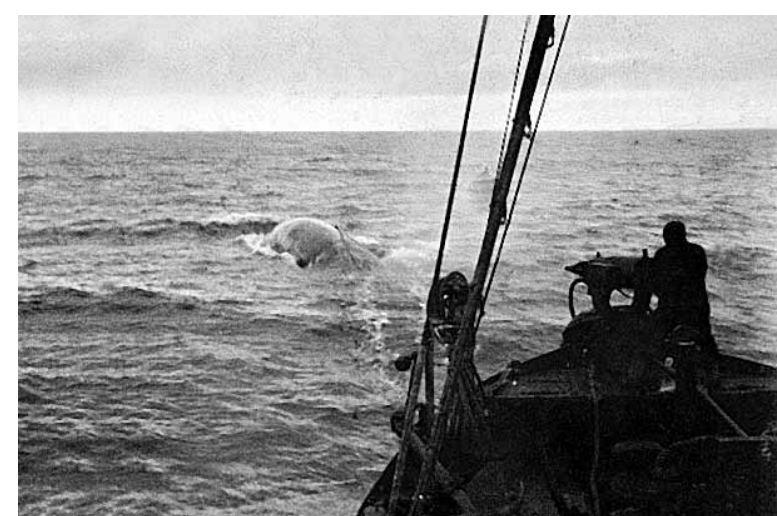

Fig. 7. La caza de la ballena desde un vapor de la Sociedad Ballenera de Magallanes. (Fotografía de E.B. Binnie, 1908. Archivo Iconográfico Instituto de la Patagonia, Universidad de Magallanes).

mares antárticos que se realizará entre diciembre de 1906 y marzo de 1907. Los periódicos regionales indicaban que en el mes de enero de 1907 la escuadrilla ballenera de la Compañía de Bahía Águila, compuesta de los vapores 'Gobernador Bories', 'Almirante Valenzuela' y 'Uribe', se encuentra en la rejion polar a caza de ballenas ${ }^{93}$. Dos meses después se informa que en la isla Elefante, la más boreal de las Shetlands del Sur, recaló al mando de Andresen sin novedad la escuadrilla ballenera, perteneciente a la compañía fundada i establecida en ésta, compuesta de los vapores 'Gobernador Bories', 'Almirante Uribe' y 'Almirante Valenzuela', después de una fructífera campaña en los mares del estrecho i sus cercanías. Se nos informa que en la última campaña, que duró 4 meses han sido pescadas 172 ballenas, algunas de un porte extraordinario ${ }^{94}$. De acuerdo a las fuentes noruegas, en la temporada 1906-1907 se habrían capturado 203 ballenas en las Shetlands del Sur (Risting 1922: 329). En el mes de abril se informa que el Gobernador Bories zarpará con rumbo a Europa, conduciendo todo el aceite beneficiado en esta última temporada ${ }^{95}$. El 19 de mayo de 1907 el buque fondea en Punta Arenas con un cargamento de aceite para conducirlo a Europa $^{96}$, vía Montevideo ${ }^{97}$.

93 El Comercio (Punta Arenas), 9 de enero de 1907.

94 El Comercio (Punta Arenas), 16 de marzo de 1907.

95 El Comercio (Punta Arenas), 16 de abril de 1907.

96 El Comercio (Punta Arenas), 20 de mayo de 1907.

97 El Comercio (Punta Arenas), 18 de mayo de 1907.
En dos ocasiones ${ }^{98}$ la flota de la Sociedad Ballenera de Magallanes se encuentra en isla Decepción con los integrantes de la Deuxième Expédition Antarctique Française [1908-1910] dirigida por el Dr. Jean Charcot ${ }^{99}$. Uno de ellos, el médico y naturalista J. Liouville ${ }^{100}$ describe con mucho detalle la captura y procesamiento de las ballenas realizada en isla Decepción, con datos sacados de nuestro diario de viaje relatando las salidas efectuadas a la caza de ballenas con el capitán Andersen, a bordo del "Almirante Uribe", y con el capitán Hansen, a bordo del "Almirante Valenzuela" de la Sociedad Ballenera de Magallanes (Liouville 1913: 219). Como lo indica Charcot, el 6 de diciembre de 1909 Liouville y Gain, acompañados por Senouque con el cinematógrafo,

98 La primera entre el 22 y el 25 de diciembre de 1908 y la segunda entre el 27 de noviembre de 1909 y el 6 de enero de 1910 .

99 Jean Baptiste Charcot (1867-1938). Nace en Neuilly-sur-Seine, el 15 de julio de 1867. Estudia medicina pero su vocación era la de explorar los mares menos conocidos. Realiza dos importantes expediciones a la Antártica, la primera en el Français (1905) y la segunda en el Pourquoi-Pas? (1908-1910). Después de haber servido en la administración británica durante la Primera Guerra Mundial, Charcot, asistido por diversos especialistas, retoma sus estudios en el Atlántico Norte. Efectúa entre 1920 y 1936 numerosos cruceros científicos que lo llevarán desde las Islas Hébridas hasta las costas orientales de Groenlandia (1925-1936). El 16 de septiembre de 1936, después de doce horas de tempestad, el Pourquoi-Pas? se hace pedazos sobre los arrecifes de Faxafjord, causando la muerte de Jean-Baptiste Charcot y todos sus compañeros, excepto uno (Hoisington 1975). Charcot publica varios libros sobre sus exploraciones: Le "Français" au pôle Sud [1906], Le "Pourquoi-Pas?" dans l'Antarctique [1911], Autour du pôle Sud [1912], Christophe Colomb vu par un marin [1928], La Mer du Groenland [1929].

100 Jacques Liouville (1879-1960) Nace en Paris, el 5 de diciembre de 1879. Estudia medicina y ciencias naturales, especializándose en zoología marina. Mientras trabaja en la facultad de medicina de Paris, es invitado por Charcot para participar en la expedición del Pourquoi-Pas? (1908-1910). A su regreso se embarca en un nuevo crucero oceanográfico, el $12^{\circ}$ Crucero del Princesse Alice II, que contaba el patrocinio del príncipe Alberto I de Mónaco. Mobilizado en 1914, Liouville toma parte como médico de un regimiento de dragones en los combates que se desarrollarán en el Marne, Bélgica En 1919 se traslada a Marruecos donde impulsará la creación del Institute Scientifiqie Cherifien y de la Société des Sciences naturelles du Maroc. Entre 1923 y 1926 Liouville toma parte de las cuatro campañas oceanográficas del SS Vanneau para la exploración de la costa atlántica de Marruecos. Muere en Rabat, Marruecos, el 15 de junio de 1960 (Dollfus 1960). 
fueron en el Almirante Uribe para una caza de ballenas y al día siguiente el Sr. y la Sra. Andresen tuvieron la excelente idea de llevarnos a todos nosotros a la caza de ballenas en el Almirante Valenzuela (Charcot 1911: 265). Podemos, entonces, considerar las descripciones de Liouville ${ }^{101}$ como relatos de primera mano tanto sobre los buques que componen la flota de la Sociedad Ballenera de Magallanes como sobre los procedimientos de captura y procesamiento de las ballenas.

El buque-factoría es un carguero adaptado para e procesamiento de ballenas a bordo. En estos cargueros se encuentran las calderas, los depósitos, los talleres y la construcción de los barriles, además que un conjunto de barriles vacíos invade, en efecto, el puente, donde ya no se percibe el suelo de la cubierta por las cuatro hileras de barriles que sobrepasan los baluartes; sus chimeneas humean permanentemente: es un procesador flotante (Liouville 1913: 207208). Estos buques- factoría son realmente grandes transportes de cerca de 4700 toneladas, que sirven como plantas flotantes con con todas las reservas necesarias de materiales, como carbón, petróleo, artillería, municiones, herramientas, tambores, provisiones, etc [... que] están provistos de un taller de reparaciones y poseen $n$ equipo completo de buceo a escafandra (op.cit.: 207-208). Estos transportes, tipo ordinario de carguero, con un gran epacio a popa y a proa que permiten las maniobras de torres y grúas; su motor, con una fuerza de 350 caballos, le permiten hacer 10 nudos de velocidad media. Una vez que el carguero llega a su destino, se ancla y cambia de naturaleza: pierde su caracter de transporte y se transforma en una fábrica, alistándose sus enormes calderas donde la grasa de la ballena recibe el efecto del vapor bajo presión para extraer aceite de los animales. Luego se instalan los estanques para concentrar y separar el aceite en diversas calidades, se sacan los barriles de los depósitos y se desatan aquellos que habían sido debidamente asegurados en la cubierta durante la travesía. Los barriles ocupan toda la borda, desde la proa a la popa, excepto en el abordaje de playa, donde un equipo de

101 La traducción desde el francés de los párrafos citados del libro de Liouville fue realizado por el autor de este trabajo. trabajadores maniobrará el material a tratar (Liouville 1913: 210-211).

La tripulación de un buque factoría tiene un estado mayor compuesto por el comandante, dos oficiales, primero y segundo, y dos jefes mecánicos. El resto se compone de un patrón, un maestro trinchador, dos maestros mecánicos, un maestro calderero varios trinchadores, caldereros, fogoneros, cocineros, marineros y camareros, que hacen un total de 40 a 50 personas (Liouville 1913: 210).

Los "cazadores" tienen de 35 a 40 metros de largo, y desplazan alrededor de 150 toneladas. Estas pequeñas embarcaciones, provistas de un poderoso motor, están construidas completamente en fierro y sirven para todos los climas. Tienen en la proa un solo mástil, provisto de un tonel llamado nido del cuervo, en el que se instala un vigía para observar la respiración de los cetáceos en el horizonte. Detrás de este mástil,

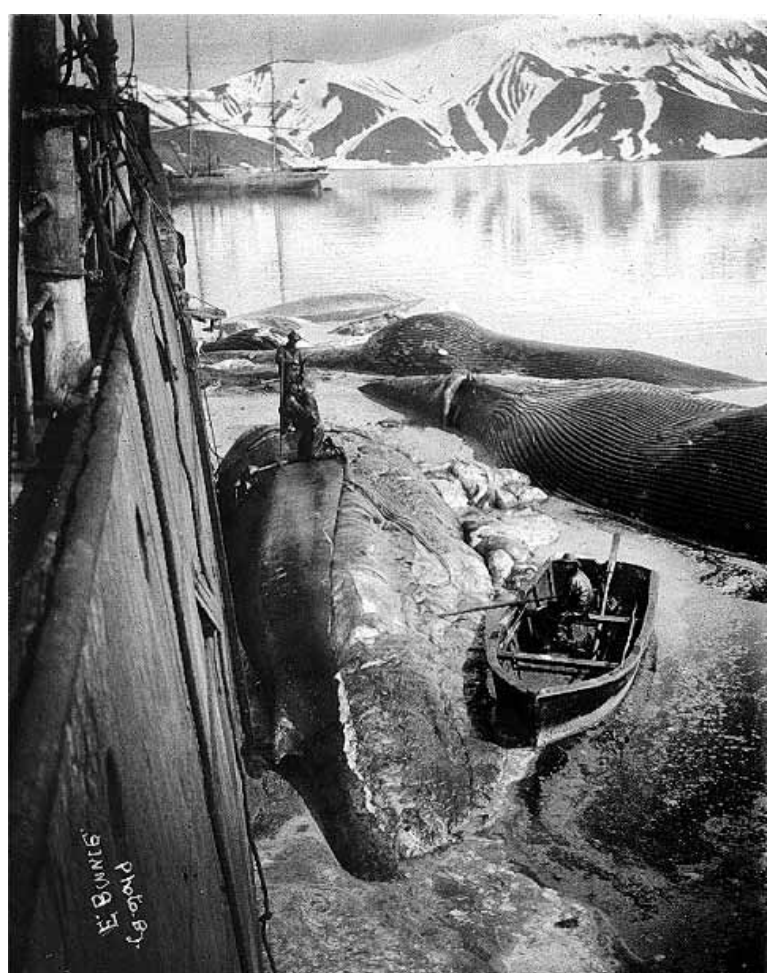

Fig. 8. El procesamiento de las ballenas al costado del Gobernador Bories. (Fotografía de E.B.

Binnie, 1908. Archivo Iconográfico Instituto de la Patagonia, Universidad de Magallanes). 
está la tapa y la claraboya del motor; luego un par de poderosos huinches, con una bobina alrededor de la cual se enrolla un cable que viene de un balde situado debajo del puente. Detrás de estas instalaciones se levanta una cabina de 2,5 $m$. cuyo techo soporta, adelante, la pasarela de madera y el puesto del timonel y, atrás, el puente de mando. A cada lado, la cocina y el baño, separadas de la cabina por un estrecho corredor. Luego, la cubierta trasera con, al centro, el panel y la claraboya del departamento del capitán. De cada lado se levantan, en lo alto de sus pescantes, las embarcaciones: a babor, una ballenera clásica y a estribor, esa frágil barca tan móvil y maniobrable, que se llama noruega. En la parte trasera, encima de la popa, un coronamiento con una rampa de madera para apoyarse. Hacia adelante, en la proa, podemos notar un extraño cañón, móvil sobre un pivote, ubicado en el eapacio del bauprés. Puede inclinarse también hacia abajo, permitiendo lanzar un tiro dentro de un radio de un metro, en un ángulo extremadamente agudo (Liouville 1913: 216-217).

La tripulación de un buque-cazador está compuesta por el capitán, que es el maestro cañonero, asistido por un segundo oficial, que comparte con tres marineros la función de tomar el timón o subir al puesto de vigía; estos tres marineros, señalador, observador y timonel rotan sus funciones. Luego están los mecánicos primero y segundo que se turnan en el comando del motor con dos fogoneros bajo sus órdenes y un cocinero quién en las horas de descanso se instala en su pequeño horno (Liouville op.cit.: 218). En términos general la tripulación de un buque-cazador está compuesta de diez personas.

En el informe de Liouville hay una detallada descripción de la caza de ballenas (op.cit.:219-226) y del procesamiento de sus carcasas (op.cit.: 227230) que no repetiremos en esta oportunidad (cf. Nicholls 2010 para un tratamieto de la información aportada por Liouville sobre estos temas).

La caza de ballenas en las aguas

patagónicas occidentales

Tenemos pocos datos sobre las operaciones de la Sociedad Ballenera de Magallanes en los alrededores de los golfos de Penas y del Corcovado.
En marzo de 1911 hay noticias del viaje del Almirante Señoret a cazar ballenas en la zona de Chiloé$^{102}$. Según informaciones "oficiales", en ese año el Rubens, fábrica flotante, actualmente [está] en Guaytecas $^{103}$. No tenemos claridad respecto de las funciones del Gobernador Bories en Chiloé, probablemente estuvo fondeado en la zona del Golfo de Penas.

En una nota aparecida en la Memoria del Ministerio de Marina de Chile correspondiente a 1912 se informa que actualmente el pontón $\mathrm{Ru}$ bens se encuentra fondeado en Bahía Águila i no en las Guaitecas, dejando constancia de la pérdida del Wilhelmine, que venía a nuestro territorio para establecer en ella una factoría ballenera dentro del archipiélago de Chiloé, agregando además que la barca Wilhelmina, de 1553 toneladas, que había sido adquirida por la Sociedad Ballenera de Magallanes, navegaba con pasavante consular ${ }^{104}$. Esta afirmación es confirmada con una noticia publicada en un diario de Chiloé donde señala que la barca Wilhemina, sale el 14 de marzo de 1912 desde Punta Arenas con dirección a Puerto Low, con un cargamento de víveres y pertrechos para la expresada sociedad [Ballenera de Magallanes ${ }^{105}$. La barca naufraga el 24 de marzo de 1912 cerca de la isla Stuven, en el canal Messier, ahogándose parte importante de la tripulación ${ }^{106}$.

Aparentemente se realizaron actividades balleneras en la zona solamente en 1911 y no volvieron a retomarse después. No podemos olvidar que la A/S Corral también operaba en esas aguas.

\section{La dinámica de la caza de ballenas}

En la Memoria del Ministerio de Marina correspondiente al año 1911 se relata el modo de

102 El Comercio (Punta Arenas), 23 de marzo de 1911.

103 Memoria del Ministerio de Marina, 1911, Archivo Nacional [Santiago de Chile], Fondo Ministerio de Marina, volúmen 1812.

104 Memoria del Ministerio de Marina de 1912, Fondo Ministerio de Marina, volumen 1860. Archivo Nacional [Santiago de Chile].

105 La Cruz del Sur (Ancud), 15 de marzo de 1912.

106 No hay información clara respecto del número de fallecidos en el naufragio. Una fuente señala que de los 23 miembros de la tripulación solo se salvaron tres (Tonnesen \& Johnsen 1982: 202). Otra indica que se ahogaron el capitán, sus dos hijas, dos pilotos y siete miembros de la tripulación, es decir 12 personas (Vargas Sáez 1999). 
operar de la flota de la Sociedad Ballenera de Magallanes. La pesca de la ballena la efectúan más o menos de la siguiente manera: Sale el Gobernador Bories i tres balleneros al mando en Jefe del Capitan Andresen, fuerte accionista de la sociedad para el Archipiélago de las Shetlands $i$ Tierras de Graham i al mismo tiempo otro ballenero a los canales i Golfo de Penas, teniendo en esa rejion al Ponton Rubens, regresando enseguida a descargar sus productos; listos nuevamente zarpan a espedicionar en Penas i sus cercanías ${ }^{107}$.

Esta salida se hace normalmente durante el mes de diciembre regresando desde la Antártica en marzo del año siguiente. Sabemos que en diciembre de 1910 salen a la Antártica el Gobernador Bories con los vapores Almirante Uribe, Almirante Valenzuela y Almirante Señoret, quedando el Almirante Montt cazando en los canales magallánicos ${ }^{108}$. La prensa magallánica señala que el Almirante Señoret zarpa durante el mes de marzo de 1911 hacia la zona de Chiloé, acompañado de los buques cazadores Almirante Uribe y Almirante Valenzuela y el buque factoría Gobernador Bories $^{109}$. El 4 de junio de 1911 fondearon en bahía Águila los balleneros Gobernador Bories y Almirante Señoret de regreso de la pesca. Según nuestras informaciones esta ha sido abundante $y$ provechosa $^{110}$.

La memoria de 1911 señala que después de esto se envía al Gobernador Bories a Europa a vender los productos del año, regresando con carbón, útiles de pesca, pertrechos, etc. Mientras el Bories se encuentra ausente, los balleneros se dedican a pescar en el Atlántico, en las cercanías del Estrecho i en los mares australes, regresando a Bahía Águila trayendo sus ballenas a remolque ${ }^{111}$.

Unos días después de su llegada de Chiloé el Almirante Señoret, acompañado del Almirante

107 Memoria del Ministerio de Marina, 1911, Fondo Ministerio de Marina, volumen 1812. Archivo Nacional [Santiago de Chile].

108 Información entregada por lan Hart, quién la obtuvo en el Falklands Islands Government Archive, de una carta enviada por el presidente de la Sociedad Ballenera de Magallanes a las autoridades del archipiélago.

109 El Comercio (Punta Arenas), 23 de marzo de 1911

110 El Comercio (Punta Arenas), 5 de junio de 1911.

111 Memoria del Ministerio de Marina, 1911, Fondo Ministerio de Marina, volumen 1812. Archivo Nacional [Santiago de Chile].
Montt, se dirigen a cazar ballenas al Atlántico ${ }^{112}$. Hay registros de viajes al Atlántico y al cabo de Hornos del Almirante Valenzuela ${ }^{113}$ y el Almirante Uribe ${ }^{114}$. El Gobernador Bories parte a Europa durante el mes de julio de 1911, regresando de su viaje a Europa, a donde fue con un cargamento de aceite de ballena por cuenta de la Sociedad Ballenera de Magallanes ${ }^{115}$ y trajo materiales diversos como ser carbón y barriles y otros para las próximas faenas de pesca que llevará a cabo en los mares del sur ${ }^{116}$. Unos días más tarde ha salido de Bahía Águila hacia las islas Shetlands la flotilla de la Sociedad ballenera. Su salida significa el comienzo de la temporada de pesca ${ }^{117}$, y el reinicio del ciclo que tendrá algunas variaciones anuales pero no muy significativas.

\section{La productividad de la Sociedad}

Ballenera de Magallanes

Las estadísticas oficiales que registraban las capturas de ballenas en diversas partes del mundo eran llevadas por la Norsk Hvalfangsteforeging [Asociación de Balleneros Noruegos] con sede en Sandefjord, Noruega, y publicadas desde 1912 en la revista Norsk Hvalfangst-Tidende [La Gaceta Ballenera Noruega]. En 1930 el gobierno noruego establece el Bureau of International Whaling Statistics para llevar un registro acucioso de las capturas de cetáceos, las que publicará anualmente en la revista International Whaling Statistics. En 1984 esta responsabilidad fue asumida por la International Whaling Commission en Cambridge, Inglaterra, que continuó recolectando y publicando los datos de capturas desde 1984/5 en el mismo formato.

Nos interesa intentar determinar el número de ballenas capturadas por la empresa y el volúmen de aceite producido durante la década en la que estuvo operando la Sociedad Ballenera de Magallanes. Las estadísticas oficiales no registran la cantidad de ballenas capturadas por el Almirante Montt en la temporada 1905-1906 ni el volúmen de aceite producido por la planta de Bahía Águi-

\footnotetext{
112 El Comercio (Punta Arenas), 12 de junio de 1911.

113 El Comercio (Punta Arenas9, 11 de junio de 1911.

114 El Comercio (Punta Arenas), 15 de julio de 1911.

115 El Comercio (Punta Arenas), 29 de noviembre de 1911.

116 Chile Austral (Punta Arenas), 30 de noviembre de 1911.

117 Chile Austral (Punta Arenas), 5 de diciembre de 1911.
} 
Tabla 2. Captura de ballenas y producción de aceite [1905-1914].

\begin{tabular}{|c|ccc|c|}
\hline TEMPORADA & Magallanes & $\begin{array}{c}\text { BALLENAS } \\
\text { Antártica }\end{array}$ & $\begin{array}{c}\text { Totales } \\
\text { Barriles }\end{array}$ \\
\hline $1905-1906$ & 129 & 0 & 129 & 2.900 \\
\hline $1906-1907$ & 171 & 203 & 374 & 8.500 \\
\hline $1907-1908$ & 152 & 252 & 404 & 8.000 \\
\hline $1908-1909$ & 172 & 416 & 588 & 11.300 \\
\hline $1909-1910$ & 93 & 420 & 513 & 13.000 \\
\hline $1910-1911$ & 106 & 433 & 539 & 13.600 \\
\hline $1911-1912$ & $i ?$ & $i ?$ & 563 & $13.900^{1}$ \\
\hline $1912-1913$ & 81 & 319 & 400 & 13.200 \\
\hline $1913-1914$ & $i ?$ & $i ?$ & 245 & \\
\hline & & & 3.755 & 97.400 \\
\hline
\end{tabular}

Fuente: International Whaling Commission, Cambridge, Inglaterra.

\begin{tabular}{|c|ccc|c|}
\hline TEMPORADA & Magallanes & $\begin{array}{c}\text { BALLENAS } \\
\text { Antártica }\end{array}$ & $\begin{array}{c}\text { ACEITE } \\
\text { Toneladas }\end{array}$ \\
\hline 1911 & 115 & 433 & 548 & 2.200 \\
\hline 1912 & 108 & 434 & 542 & 2.203 \\
\hline 1913 & 3 & 344 & 347 & 2.036 \\
\hline 1914 & 5 & 304 & 309 & 2.068 \\
\hline & & & & \\
\hline TOTALES & 231 & 1.515 & 1.746 & 8.507 \\
\hline
\end{tabular}

Fuente: Memorias del Ministerio de Marina de Chile, Santiago, Chile.

$1 \quad$ La cifra exacta es 13869.

la. Sin embargo, el historiador noruego Tønnesen (1967, 2: 411) señala que las ballenas capturadas serían 129 , con una producción total de 2,900 barriles de aceite (casi 500 toneladas). Para la temporada 1906-1907 se indica que la Sociedad Ballenera de Magallanes captura 374 ballenas que produjeron en total 8,500 barriles de aceite; de ellas 203 habrían sido cazadas en las Shetlands del Sur y el resto, 171, en aguas del estrecho de Magallanes (Risting 1922: 329).

En la Tabla 2 mostramos un resumen con las capturas de ballenas y la producción de aceite entre 1905 y 1915 de la Sociedad Ballenera de Magallanes, según los datos que se manejan en la International Whaling Commission desagregados, cuando es posible, en capturas en "aguas antárticas" y en "aguas magallánicas"118. Nos parece

118 Datos proporcionados por Cherry Allison, del Secretariat de la International Whaling Commission, Cambridge, Inglaterra. interesante incorporar también en esta tabla los datos que aparecen en las memorias del Ministerio de Marina de Chile sobre estas materias (período 1910-1914), cifras que no coinciden necesariamente con las manejadas por los organismos internacionales, pero que tampoco se alejan significativamente ${ }^{119}$.

\section{EL DESTINO DE LA FLOTA}

De los once buques que formaron la flota de la Sociedad Ballenera de Magallanes se quedaron en Chile, luego de la disolución de la empresa, solamente tres: el cazador Almirante Señoret y los pontones Cornelia Jacoba y Rubens.

119 Estas discrepancias se pueden explicar, al menos parcialmente, debido a que los períodos considerados no son los mismos. Las estadísticas chilenas se refieren al año calendario, es decir, desde enero a diciembre; en cambio en las estadísticas internacionales se considera como año el lapso que va desde abril de un año a marzo del año siguiente. 
Uno se hundió en 1912 en aguas nacionales: el Wilhelmine. Los siete restantes fueron vendidos en el extranjero: los "almirantes" Montt, Uribe y Valenzuela, en Italia, el Almirante Goñi en Noruega, el Gobernador Bories ex Wordsworth, en Inglaterra, el Gobernador Bories ex Senator en Estados Unidos y el Telefon en Escocia. Revisemos primero lo ocurrido con los buques vendidos al extranjero.

El primero en venderse en el Reino Unido fue el Telefon ${ }^{120}$. En 1910 fue adquirido por Lovart Steamship Co. Ltd. [Bo'ness, Falkirk, Escocia] y renombrado Kinneil. El 30 de octubre de 1913 se hunde cerca de Skagen, Dinamarca, luego de colisionar con un vapor alemán, el Denebola (Hart 2006: 332).

El Gobernador Bories ex Wordsworth, es vendido en 1914 en Inglaterra ${ }^{121}$. En 1915 es hundido por el Almirantazgo Británico como buque de bloqueo en Burra Sound, Scapa Flow, Orkney Islands, Escocia, siendo uno de los primeros en usarse para estos fines ${ }^{122}$. El naufragio no fue dispersado por explosivos y permanece sustancialmente intacto (aunque carece de superestructura) y hoy es regularmente visitado por buzos deportivos ${ }^{123}$.

Los vapores Almirante Montt, Almirante Valenzuela y Almirante Uribe fueron vendidos durante el mes de febrero de 1916, a través de Duncan, Fox \& Cia (Bravo Valdivieso 2005: 24), al armador noruego O. B. Linaae (Parker de Bassi 1990:31) ${ }^{124}$ y posteriormente, entre julio y septiembre del mismo año, traspasados a la Regia

120 Nómina de las transferencias efectuadas en el registro de la Marina Mercante Nacional en el año de 1910. Memoria del Ministerio de Marina, 1766. Fondo Ministerio de Marina, volumen 1979. Archivo Nacional [Santiago de Chile].

121 Nómina de los registros cancelados por las causas que se indica en el año de 1914. Memoria del Ministerio de Marina, 1914. Fondo Ministerio de Marina, volumen 1979. Archivo Nacional [Santiago de Chile].

122 http://canmore.rcahms.gov.uk/en/site/102319/details/ gobernador+bories+burra+sound+scapa+flow+orkney (Consultado el 30 de julio del 2010).

123 http://www.divernet.com/Wrecks/wreck tours/159456/ wreck tour 22 the gobernadore bories.html (Consultado el 30 de julio del 2010).

124 Parker de Bassi habla, en realidad, de un empresario de Sandefjord de apellido Linan (op.cit.: 31). De acuerdo a la información proporcionada por el investigador alemán Axel Kuehn, este empresario sería O. B. Linaae, de Sandefjord.
Marina Italiana ${ }^{125}$. Los tres buques zarpan el 20 de junio de 1916 desde Punta Arenas rumbo a Montevideo y luego a Europa, llevando como emblema la bandera noruega (Bravo Valdivieso 2005: 24) ${ }^{126}$. La Marina Italiana cambia dos veces los nombres de los tres buques: el 16 de septiembre de 1916 pasan a llamarse Leopardo, Tigre y Pantera, y el 31 de enero de 1917 Voragine, Vigilante y Vortice, respectivamente. La Marina Italiana los usará como patrulleros durante la Primera Guerra Mundial y dos de ellos serán dados de baja en 1920 y el otro en $1932^{127}$.

El Voragine, ex Leopardo, ex Almirante Montt es adquirido en 1920 por A. Serra \& B. Berardi, del puerto de Ancona, Italia, y su nombre cambiado por el de María Stefanía ${ }^{128}$. Luego, en 1928, es comprado por un empresario del puerto de El Pireo, Grecia, cambiando su nombre por el de Alecos. En 1930 será traspasado a Sotiropoulus \& Raftopoulus [Laurium, Grecia] y su nombre cambiado a Ithacos ${ }^{129}$; en 1933 lo tendrá K. Kyriacopulus [El Pireo, Grecia] modificando su nombre al de Aghios Spyridon ${ }^{130}$, en 1937 a N.G. Maniatis [El Pireo, Grecia] cambiando nuevamente su nombre el de Anna María ${ }^{131}$. Es hundido en 1943. El Vigilante, ex Tigre, ex Almirante Valenzuela es adquirido en 1932 por Vicenzo Salvi [Ancona, Italia], y modificado instalando un motor diesel de 6 cilindros y 44 NHP, construido por Humboldt Deutz

125 Los buques balleneros Corral y Noruega, de la Sociedad Ballenera Adolfo Andresen también se vendieron a la Regia Marina Italiana, zarpando de Punta Arenas, con destino a Nápoles, el 1 de agosto de 1916 (Bravo Valdivieso 2005: 24), los que serán rebautizados como Balena y Capodoglio respectivamente.

126 En la prensa magallánica se entregan noticias confusas sobre este tema: El Comercio (Punta Arenas) señala el 17 de febrero de 1916 que la Sociedad Ballenera de Magallanes gestiona la venta de los vapores que tiene destinados a cabotaje y el 30 de junio de ese mismo año indica que los vapores de la Sociedad Ballenera de Magallanes han sido vendidos a una firma japonesa. El diario La Unión (Punta Arenas) del 21 de junio de 1916 señala que el "Almirante Montt" ha salido hacia Montevideo. Parker de Bassi (1990: 39) y Bravo Valdivieso (2005: 24) dicen que los buques habrían sido adquiridos por Inglaterra.

127 Unitá della Marina Italiana dal 1860 a oggi. http://www. marina.difesa.it/storia/almanacco/navi017.asp (Consultado el 14 de abril del 2010).

128 Lloyd's Register of British \& Foreign Shipping, 1923-24.

129 Lloyd's Register of British \& Foreign Shipping , 1930-31.

130 Lloyd's Register of British \& Foreign Shipping ,1933-34.

131 Lloyd's Register of British \& Foreign Shipping, 1937-38. 
Motoren, A.G. Köln-Deutz, y su nombre cambiado por el de Bianca María ${ }^{132}$. En 1940 es requisado por la Marina Italiana, renombrado F-104 y hundido el 16 de noviembre de 1943 por aviones alemanes cerca de la isla de Leros, una de las islas del archipiélago del Dodecaneso, Grecia, que se encuentra situado frente a las costas de Turquía. No tenemos datos respecto del destino del Vórtice, ex Pantera ex Almirante Uribe después de ser dado de baja en 1920 por la Marina Italiana, pero probablemente estuvo registrado en algún puerto del Mediterráneo, en Grecia, Turquía o Egipto ${ }^{133}$.

El Almirante Goñi es el único de los cazadores que continuará en el negocio ballenero. En 1916 es vendido a A/S Hektor, empresa de Tonsberg, Noruega, para seguir operando en aguas antárticas, en las Shetlands del Sur. En 1924 es transferido a la Sociedad Ballenera Española, en Algeciras, España y en 1925 es adquirido por Winge \& Co., de Oslo Noruega y su nombre cambiado por el de Veslegut. En 1927 es comprado por A/S Blomvåg, empresa de Sandefjord, Noruega, continuando sus operaciones balleneras desde la estación terrestre de Blomvåg, en la costa occidental de Noruega, hasta el año 1939. Ese año es requisado por la Marina de Noruega y en 1940 tomado por las Fuerzas Alemanas de Ocupación de Noruega y su nombre cambiado por el de Ratte (V 5501). Después de la guerra es devuelto a sus antiguos dueños, A/S Blomvåg, Bergen, Noruega, recuperando su antiguo nombre de Veslegut. En 1947 es vendido por la empresa y, luego de pasar por varias manos y cambios de nombre, sus propietarios actualmente son Jon Anton Henrik Swensen, Bolga, Noruega y Håvard Eide, Kvæefjord, Noruega, y el nombre del buque ha vuelto a ser Veslegut.. Se ha presentado una propuesta para declararlo patrimonio cultural protegido cuyo pronunciamiento definitivo por parte de las autoridades está aún pendiente ${ }^{134}$.

El Gobernador Bories ex Senator, fue vendido el 12 de mayo de 1916 en US\$780,000 a la Chile Exploration Company, Nueva York, USA,

132 Lloyd's Register of British \& Foreign Shipping, 1935-36.

133 Gran parte de la información sobre estos buques fue entregada por Axel Kuehn, quién la obtuvo de diversas fuentes italianas.

134 La información sobre la historia del Veslegut ex Almirante Goñi la ha reunido y proporcionado gentilmente Håvard Haraldsønn Salen, de Borkenes, Noruega. para ser usado por la Sherman Steamship Corp., en el transporte de cobre y suministros entre Chile y Nueva York, cambiando su nombre por el de Sherman (Weed 1918: 1846-1847). Durante el mes de septiembre de 1916 se informa desde Nueva York que el vapor norteamericano Sherman llegó ayer con una carga record de cobre chileno desde Antofagasta. Consiste de 6,500 toneladas en lingotes y barras y fue valorada en US\$ 4,000,000. El cobre estaba consignado a diversas firmas de Nueva York $^{135}$. Cuando Estados Unidos entra en la Primera Guerra Mundial el Sherman fue transferido el 30 de agosto de 1918 por el United States Shipping Board $^{136}$ a la U.S. Navy y el 23 de noviembre de 1918 su nombre fue cambiado por el de Durham y destinado al Naval Overseas Transportation Service $^{137}$. Fue dado de baja el 29 de abril de 1919 y regresado a sus propietarios, recobrando su antiguo nombre ${ }^{138}$. El Sherman fue vendido en Italia y desguazado en 1924 en el puerto de Génova.

Como ya lo mencionamos, los tres buques que permanecieron en Chile fueron el Almirante Señoret, el Cornelia Jacoba y el Rubens.

El vapor Almirante Señoret fue adquirido en $1914^{139}$ por la Sociedad Vicente \& Antonio Ku-

135 New York Times (Nueva York, USA), 17 de septiembre de 1916.

136 El United States Shipping Board fue establecida por el Shipping Act el 7 de septiembre de 1916 con la finalidad de restaurar la antigua gloria de la Marina Mercante Norteamericana, pero la entrada de Estados Unidos en la Primera Guerra Mundial la transformó en una agencia militar cuyo objetivo era mantener una línea de comunicación entre América y Europa. El Shipping Board se encargó de adquirir, mantener y operar buques mercantes para cumplir con tanto con la defensa nacional como con el comercio exterior y doméstico de los Estados Unidos durante la Primera Guerra Mundial (Hurley 1927).

137 El Durham hizo dos viajes desde Nueva York a Bordeaux y Marseille, Francia, entre el 10 de septiembre y el 29 de diciembre de 1918 y entre el 24 de enero y el 10 de abril de 1919 jugó un importante papel en los esfuerzos realizados por los Estados Unidos en los Balcanes llevando alimentos desde Nueva York a distintos puertos del Adriático. Ver http://www.navsource.org/archives/12/173345.htm. (Consultado el 28 de agosto del 2010).

138 Dictionary of American Naval Fighting Ships. En http:// www.hazegray.org/danfs (Consultado el 28 de agosto del 2010).

139 Nómina de las transferencias efectuadas en el registro de la Marina Mercante Nacional en el año de 1914. Memoria del Ministerio de Marina, 1914. Fondo Ministerio de Marina, volumen 1979. Archivo Nacional [Santiago de Chile]. 
sanovic [Punta Arenas, Chile] ${ }^{140}$, quiénes lo usaron para el servicio de cabotaje entre Punta Arenas y los establecimientos productivos que tenían en Isla Riesco (Martinic 2009: 207), y lo mantuvieron en su poder algunos años ${ }^{141}$. En 1922 es adquirido por un grupo de empresarios de Porvenir, quiénes formaron la Comunidad Vapor Almirante Señoret [Porvenir, Chile], para atender el tráfico mercante entre ambas costas del estrecho de Magallanes (Martinic, 1999: 51). En 1936 el Ministerio de Fomento compra el vapor por $\$ 230,000$ a la Comunidad Vapor Almirante Señoret para destinarlo al servicio de la Dirección General de Pesca y Caza para el fomento de la pesca ${ }^{142}$. El Presidente de la República en su mensaje leído en la apertura de las sesiones ordinarias del Congreso Nacional el 21 de Mayo de 1937 informa sobre este tema señalando que se ha adquirido el vapor 'Almirante Señoret' destinado a proveer regularmente de pescado $y$ marisco a los habitantes de la capital y poblaciones del centro del país y, al mismo tiempo, proporcionar todo género de protección y auxilio a los pescadores durante y después de su trabajo ${ }^{143}$. La Dirección General de Pesca y Caza establece un convenio con la Sociedad Muzard, Bellet y Cia ${ }^{144}$,

140 Sociedad formada por los dos hermanos en 1909 con la finalidad de establecer explotaciones ganaderas en Magallanes "para el abastecimiento alimentario de la población, así como a toda la gama de actividades complementarias y derivadas" (Martinic 2009: 206). El Almirante Señoret aparece como el único vapor de la sociedad en la Lista alfabética de los armadores de la Marina Mercante nacional en 31 de diciembre de 1916. Memoria del Ministerio de Marina correspondiente al año 1916. Santiago: Nacional, 1918.

141 El Almirante Señoret, vapor de 110,31 toneladas gruesas y 55,16 toneladas de registro, aparece en la Guía Comercial de Magallanes de 1918, como propiedad de V. y A. Kusanovich y Cía. En la Guía Marítima de Chile, correspondiente al año 1922, se indica como su dueño a José Iglesias, de Punta Arenas (Swett 1923-24: 304-305).

142 Decreto 2,675 [Ministerio de Fomento] del 26 de diciembre de 1936. Diario Oficial (Santiago de Chile), 3 de febrero de 1937.

143 Mensaje leído por S. E. el Presidente de la República en la apertura de las Sesiones Ordinarias del Congreso Nacional, en 21 de Mayo de 1937. Diario Oficial (Santiago de Chile), 22 de mayo de 1937.

144 La Sociedad Muzard y Bellet Limitada, sociedad comercial colectiva, de responsabilidad limitada, se había constituido en Santiago el $1^{\circ}$ de junio de 1939 y cuyo giro era la explotación de la industria pesquera, comprendiéndose bajo esta denominación, la producción, adquisición, elaboración, distribución y venta de pescado, marisco y cualquier producto del mar. Diario Oficial (Santiago de Chile), 6 de junio de 1939. entregándole en arriendo, entre otras cosas, el vapor Almirante Señoret para la explotación de la industria pesquera, entendiéndose por tal la producción, distribución y venta de los productos del mar ${ }^{145}$, y también para ser empleado en el cabotaje público, siempre que los concesionarios obtengan, de quien corresponda, el permiso necesario para ello, obligando a los concesionarios a hacer, a lo menos, una recalada quincenal a la isla La Mocha, con el vapor 'Almirante Señoret' y a proporcionar "sin costo alguno, dos pasajes de primera clase a los funcionarios del Ministerio de Tierras y Colonización, en el vapor 'Almirante Señoret' cuando éstos, por asuntos del servicio, tengan que trasladarse a los puntos en que haga recalada dicho vapor ${ }^{146}$. En 1941 la Dirección General de Pesca y Caza transfiere a la Corporación de Fomento de la Producción un vapor de 55 toneladas de registro, matriculado con el nombre de Almirante Señoret ${ }^{147}$. En 1942 la CORFO forma la Compañía Pesquera Arauco Sociedad Anónima, cuyo objetivo era la explotación de la pesca en un sentido amplio y la distribución y venta de sus productos elaborados, en el país y en el extranjero ${ }^{148}$. Entre los bienes que la CORFO entrega a la Pesquera Arauco S.A. está el vapor Almirante Señoret, cuyo nombre es cambiado por el de Bonito $^{149}$. La sociedad anónima no tiene éxito y en

145 Decreto 2,475 [Ministerio de Fomento] de 13 de Diciembre de 1939. Ministerio de Fomento, Decretos, Volumen 1553 Archivo Nacional [Santiago de Chile].

146 Decreto № 5 [Ministerio de Tierras y Colonización], del 8 de enero de 1941, que modifica el Decreto 2,475 [Ministerio de Fomento] de 13 de Diciembre de 1939. Diario Oficial (Santiago de Chile), 13 de mayo de 1941.

147 Decreto 2,708 [Ministerio de Fomento], 1941. Diario Oficial (Santiago de Chile), 7 de febrero de 1942.

148 Extracto de los Estatutos de la Compañía Pesquera Arauco, Sociedad Anónima. El capital social de la empresa está formado $\$ 12.500 .000$ correspondientes a 625.000 acciones con un valor nominal de $\$ 20$ cada una. La Corfo mantiene en su poder algo menos de $78 \%$ de las acciones colocando a disposición de particulares el $22 \%$ restante. El Gobierno autoriza la existencia de la sociedad y aprueba sus estatutos mediante del D.S N ${ }^{\circ}$ 2,664 [Ministerio de Hacienda] del 7 de agosto de 1942. Diario Oficial (Santiago de Chile), 22 de septiembre de 1942.

149 Nos imaginamos que este es el momento que se produce el cambio de nombre, aunque no tenemos los datos precisos. En la Guía Marítima de Chile correspondiente al año 1946 aparece el vapor Bonito ex Almirante Señoret de propiedad de la Compañía Pesquera Arauco Limitada (Swett 1948: 304-305). 
1946 la CORFO forma con la Sociedad Montoya y Compañía Limitada, de Talcahuano, una sociedad de responsabilidad limitada, denominada Compañía Pesquera Arauco Limitada, cuyo objetivo era la explotación de la industria pesquera y sus derivados y la distribución y venta de sus productos en el país y en el extranjero, pagando su aporte con la transferencia en propiedad de los bienes de la ex Compañía Pesquera Arauco S.A., formando parte de ese aporte las naves Albacora y Bonito, de propiedad de la Corporación de Fomento de la Producción ${ }^{150}$. No tenemos información sobre el destino final del vapor Bonito, probablemente fuera de servicio en la década de los 50.

El Cornelia Jacoba y el Rubens eran, a fines de 1916, los últimos buques de la Sociedad Ballenera de Magallanes y con su venta se cerraba el último capítulo de su breve historia. Son sacados juntos a remate en Punta Arenas el 26 de noviembre de $1916^{151}$ siendo ambos adquiridos por la empresa Braun \& Blanchard de Punta Arenas.

El Cornelia Jacoba servirá de pontón en Punta Arenas, función que cumple, al menos, hasta el 31 de diciembre de $1917^{152}$. En 1918 es vendido a Castro, Villegas \& Co [Valparaíso, Chile], luego a Bórquez, Blanco \& Co. [Valparaíso, Chile] y finalmente a Bruna, Sampaio \& Co. [Valparaíso, Chile], quiénes le instalan un motor a vapor, compuesto, de 350 HP (Swett, 1922), renombrándolo como Don Roberto ${ }^{153}$. En 1919 es transferido a la sociedad anónima denominada Compañía Nacional de Vapores, [Valparaíso, Chile $]^{154}$. Naufraga, luego de una colisión, en la

150 Extracto Compañía Pesquera Arauco Ltda. El capital social de la nueva compañía es de \$6.500.000 aportando la CORFO \$ 5.500 .00 y la Sociedad Montoya y Cia. Ltda \$ 1.000.000. Diario Oficial (Santiago de Chile), 7 de marzo de 1946.

151 La Unión (Punta Arenas), 16 de noviembre de 1916, El Comercio (Punta Arenas), 24 de noviembre de 1916.

152 Cuadro de las chatas que existen fondeadas en los diferentes puertos del territorio en 31 de diciembre de 1917. Memoria del Ministerio de Marina correspondiente al año 1917. Santiago: Nacional, 1918.

153 Transferencias efectuadas en el Rejistro Jeneral de la Marina Mercante Nacional durante el año 1918. Memoria del Ministerio de Marina correspondiente al año 1918. Santiago: Nacional, 1919.

154 Transferencias efectuadas en el Rejistro Jeneral de la Marina Mercante Nacional durante el año 1919. Memoria del Ministerio de Marina correspondiente al año 1918. Santiago: Nacional, 1919. bahía de Valparaíso el 10 de junio de 1926 (Vargas Saéz 1999: 178).

El Rubens permanece en poder de Braun \& Blanchard hasta el momento que, por disposición de la Gobernación Marítima de Magallanes, debe ser hundido el 23 de junio de 1927 frente a Punta Arenas (Vargas Saéz 1999: 181). No tenemos mayores antecedentes respecto del uso que hizo la empresa de este viejo buque, el más antiguo de todos los que tuvo la Sociedad Ballenera de Magallanes.

\section{PALABRAS FINALES}

La Sociedad Ballenera de Magallanes tuvo once buques pero ocupó en actividades balleneras sólo ocho: cinco cazadores, dos buques factoría y un velero que hizo las funciones de buque de apoyo. Los cinco cazadores fueron construidos en Noruega, cuatro en Framnaes y el quinto en Nylands. Los cuatro cazadores construidos en Framnaes eran nuevos y el de Nylands de segunda mano. Los dos buques factoría eran antiguos buques, uno construido en 1882 y el otro en 1872, acondicionados para el procesamiento de la ballena, el primero en Framnaes y el otro en Bahía Águila, Punta Arenas. El principal problema de la flota estaba en lo antiguo y lo pequeño de su buque factoría, el "primer" Gobernador Bories. La Sociedad lo reemplazará aunque fue demasiado tarde pues cuando el nuevo buque llega a Punta Arenas, ya se había decidido abandonar la captura de ballenas, disolver la empresa y vender todos sus activos. El 26 de noviembre de 1916 se rematan tanto las instalaciones de bahía Águila como los dos últimos buques que quedaban, los pontones Cornelia Jacoba y Rubens.

Durante un período de diez años se cazaron ballenas desde tres puntos geográficos, bahía Águila (Punta Arenas), bahía Balleneros (isla Decepción, Antártica) y bahía Low (islas Guaitecas), utilizando tanto estaciones terrestres como buques factoría anclados en una bahía protegida. Se capturó, según las estadísticas oficiales internacionales, un total de 3.755 ballenas que produjeron algo menos de 100.000 barriles de aceite, con promedios cercanos a las 400 ballenas y los 10.000 barriles de aceite anuales.

Cada uno de los buques empleados por la Sociedad Ballenera de Magallanes tuvo su propia 
historia, compartida durante algunos años con los otros, pero siempre con una trayectoria particular y un destino similar. El único actualmente a flote es el Veslegut ex Almirante Goñi., buque que pronto se incorporará a la lista de monumentos históricos protegidos por el Gobierno de Noruega. El conocimiento y puesta en valor del patrimonio ballenero magallánico es una tarea a la que hemos querido contribuir con este trabajo. Queda mucho por hacer. Aunque no se puedan proteger los buques, sus imágenes y descripciones pueden estar entre nosotros, sin que lo sepamos. Las ruinas de las instalaciones balleneras en bahía Águila son un llamado poderoso para que nos ocupemos del patrimonio material de una industria de relevancia no sólo para Magallanes sino para el país (Nicholls 2010).

\section{AGRADECIMIENTOS}

Mis agradecimientos a los investigadores Klaus Barthelmess, Axel Kuehn y Max Buhl, de Alemania, a Gunnar Stenersen, Harald Fevang, Ode Galteland y Håvard Salen, de Noruega, a Ian Hart, del Reino Unido, a Sigúr Dögg Kvaran, de Islandia, por sus valiosas informaciones sobre los buques de la Sociedad Ballenera de Magallanes. También mis agradecimientos para Damián Duque, Ignacio Sandoval y Samantha Miranda, quiénes me ayudaron con la búsqueda de papeles en el Archivo Nacional de Santiago de Chile. De inestimable ayuda fue Raimundo Silva, encargado de la Biblioteca Histórica de Museo Naval y Marítimo de Valparaíso. Este trabajo ha sido escrito como parte del Proyecto FONDECYT 1080115 La cacería de ballenas en las costas de Chile: una mirada desde la antropología.

\section{FUENTES DE CONSULTA}

a) Referencias citadas

AAGARD, B. 1930 Fangst og Forskning i Sydishavet. Gyldendal Norsk Forlag, Oslo.

ADIE, S. \& B. L. BASBERG 2009. The first antarctic whaling season of Admiralen (1905-1906). The diary of Alexander Lange. Polar Record 45 (234): 243-263

AGUAYO-LOBO A., D. TORRES \& J. ACEVEDO 1998. Los mamíferos marinos de Chile: I. Cetacea. Serie Científica INACH 48: 19-159.
BOGEN, H.S.I 1948 A/S Framnaes Mek Vaerksted, 1898 1948. Dreyers Forlag, Oslo.

BOGEN, H.S.I 1953 Aktieselskap Ørnen 1903-1953, 50 års hvalfangst. Kommandør Chr. Christensens Hvalfangstmuseum, Sandefjord.

BRAUN, M. 1985 Memorias de una vida colmada, Buenos Aires, Gaglianone

BRAVO VALDIVIESO, G. 2005. La primera Guerra mundial en las costas de Chile. Una neutralidad que no fue tal. Altazor, Viña del Mar.

BROOME, H.A. 1913 The Log of a Rolling Stone. The Riverside Press Limited, Edinburgh.

BROWN, S.G. 1976 Modern whaling in Britain and the northeast Atlantic Ocean. Mammal Review, 6 (1): 25-36.

CHARCOT, J. 1911. The voyage of the 'Why Not?' in the Antarctic: the journal of the Second French South Polar Expedition, 1908-1910 [version inglesa de Philip Walsh]. Hodder and Stoughton, London.

DAVIS, L.E., R.E. GALLMAN y K. GLEITER. 1997. In pursuit of Leviathan: technology, institutions, productivity and profits in american whaling, 1816-1906. The University of Chicago Press, Chicago.

DOLLFUS, R. Ph. 1960. Docteur Jacques Liouville (18791960). Bulletin de la Société des Sciences Naturelles et Physiques du Maroc, 40: 265-268.

DUQUE, D. 2010. Arponeros del fin del mundo. Tesis para optar al Título de Antropólogo. Universidad Academia de Humanismo Cristiano, Santiago.

FILIPPI, A. 1997. El comodoro Andresen y la ballenería antártica chilena. Revista de Marina, 115(3): 247-257.

HART, I. 2001 Pesca. The history of the Compañia Argentina de Pesca, Sociedad Anónima, of Buenos Aires. Aidan Ellis Publishing, Salcombe.

HART, I. 2006. Whaling in the Falkland Islands Dependencies, 1904-1931. Herefordshire: Pequena.

HART, I. 2009. Antarctic Magistrate. A life through the lens of a camera. Pequena, Herefordshire.

HEADLAND, R. 1989 Chronological lists of antartic expeditions and related historical events. University of Cambridge Press, Cambridge.

HEYBURN, H.R. \& G. STENERSEN 1989 The wreck and salvage of SS Telefon. Polar Record 25 (152): 51-54.

HOHMAN, E.P. 1935 American and Norwegian whaling: a comparative study of labor and industrial organization. TheJournal of Political economy, 43 (5): 628-652.

HOISINGTON, W. A. Jr. 1975. In the Service of the Third French Republic: Jean-Baptiste Charcot (1867-1936) and the Antarctic. Proceedings of the American Philosophical Society, 119 (4): 315-324. 
HURLEY, E.N. 1927. The bridge to France. J. B. Lippincott Co, Philadelphia \& London.

JACKSON, G. 1978. The British Whaling Trade. A \& C Black Publishers Ltd., London.

LIOUVILLE, J. 1913. Cétacés de l'Antarctique (Baleinoptères, ziphiidés, delphinidés). En Deuxième expédition antarctique française (1908-1910) commandée par le Dr Jean Charcot. Sciences naturelles: documents scientifiques. Masson et Cie, Paris.

LØDRUP, H. P. 1951. A/S Akers Mek. Verksted, 1841-1951. A/S Akers Mek. Verksted, Oslo.

MARTINIC, M. 1972. Nuevos antecedentes sobre actividades nacionales en el territorio antártico durante las primeras décadas del siglo XX. Anales del Instituto de la Patagonia, 3(1-2): 31-41.

MARTINIC, M. 1973. Actividad lobera y ballenera en Magallanes y Antártica, 1868-1916. Revista de Estudios del Pacífico, 7: 7-26.

MARTINIC, M. 1975. Adolfo Andresen, pionero de la caza ballenera chilena. Boletín Informativo del Instituto Antártico Chileno, 5: 7-13.

MARTINIC, M. 1977. Antecedentes históricos sobre la caza de cetáceos en Chile. Anales del Instituto de la Patagonia, 8: 313-315.

MARTINIC, M. 1987. Navegantes norteamericanos en aguas de Magallanes durante la primera mitad del siglo XIX. Anales del Instituto de la Patagonia, 17: 11-17.

MARTINIC, M. 1999 [1978]. La inmigración croata en Magallanes. Impresos Vanic, Punta Arenas.

MARTINIC, M. 2004. Antecedentes históricos sobre la caza de cetáceos en Chile. Boletín Antártico Chileno, 23(1): 7-12.

MARTINIC, M. 2009. Vicente Kusanovic M., pionero colonizador. Recuerdo de sus reveses fundarios. Magallania 37(2):205-226.

NAVARRO, L. 1907. Censo jeneral de población, edificación, industria, ganadería i minería del territorio de Magallanes, República de Chile. Imprenta de El Magallanes, Punta Arenas.

NICHOLLS, N. 2010. La Sociedad Ballenera de Magallanes: de cazadores de ballenas a héroes que marcaron la soberanía nacional. Historia (Santiago), 43: 41-78

PARKER DE BASSI, M.T. 1990 El Herzogin Cecilie y la Barca Tinto. Tusitala, Santiago.

RIEGEL R. 1921. Merchant vessels. D. Appleton \& Co., New York \& London.

RISTING, Sigurd 1922. Av hvalfangstens historie. J. W. Cappelens Forlag, Kristanía (Oslo).
SIGURJÓNSSON, J. \& TH. GUNNLAUGSSON 2006. Revised catch series and cpue for fin whales taken from the early modern whaling land stations in Iceland. IWC SC/58/PFI4. http://iwcoffice.org/documents/ sci_com/ sc58docs/ sc-58-pfi4.pdf.

SWETT, R. 1922. Guía Maritima de Chile, 1923-24. Imprenta Victoria, Valparaíso.

SWETT, R. 1948. Guía Marítima de Chile, $2^{\circ}$ ed. Imprenta Victoria, Valparaíso.

TØNNESEN, J.N. 1967. Den moderne hualfangsts historie, Opprinnelse og utvikling. Tomo. 2. Henriksens Sandefjord, Oslo.

TØNNESEN, J.N. y A.O. JOHNSEN, 1982. The History of Modern Whaling. University of California Press, Berkeley and Los Angeles.

VARGAS SAÉZ, J.F., 1999. Historial del mar de Chile. Algunos siniestros marítimos acaecidos en el siglo XX. Imprenta y Litografía Soto Ltda., Valparaíso.

WEED, W.H., 1918. A manual of the mining industry of the world. Mines Publications Inc., New York.

\section{b) Periódicos}

Chile Austral [Punta Arenas], 1908-1916.

El Comercio [Punta Arenas], 1905-1916.

El Diario Oficial [Santiago de Chile], 1905-1916

La Cruz del Sur [Ancud], 1910-1914.

La Unión [Punta Arenas], 1912-1916.

c) Libros de Registro de Buques

American Lloyd's Register of American and Foreign Shipping [Estados Unidos], 1859-1900.

Det Norske Veritas [Noruega], 1905-1913.

Lloyd's Register of British \& Foreign Shipping [Reino Unido], 1871-1900, 1922/23, 1930-1936.

The Marine Engineer [Reino Unido], 1882, 1893, 1900.

Record of American \& Foreign Ships [Estados Unidos], 18711900.

Lista Oficial de la Marina Mercante Nacional. En Memoria del Minsiterio de Marina de Chile [Santiago], 19051916.

d) Fuentes inéditas

Notario de Magallanes, 1905-1916, Archivo Nacional [Santiago de Chile]

Memoria del Ministerio de Marina, 1910-1920, Fondo Ministerio de Marina, Archivo Nacional [Santiago de Chile]. 
Decretos, 1905-1916, Fondo Ministerio de Marina, Archivo Nacional [Santiago de Chile].

Decretos, 1905-1916, Fondo Ministerio de Hacienda, Archivo Nacional [Santiago de Chile]
Correspondencia Recibida, 1905-1916, Archivo Braun Menéndez, Museo Regional de Magallanes [Punta Arenas. Chile]. 